\title{
Temporal Upscaling of Rice Evapotranspiration Based on Canopy Resistance in a Water-Saving Irrigated Rice Field
}

\author{
Xiaoyin LiU, Junzeng Xu, And Shinong Yang \\ College of Agricultural Science and Engineering, and State Key Laboratory of Hydrology-Water Resources \\ and Hydraulic Engineering, Hohai University, Nanjing, Jiangsu, China \\ YUPING LV \\ College of Hydraulic Science and Engineering, Yangzhou University, Yangzhou, Jiangsu, China
}

YANG ZHUANG

Changzhou City Urban Flood Control Project Management Office, Changzhou, Jiangsu, China

(Manuscript received 7 November 2019, in final form 5 June 2020)

\begin{abstract}
An important element of the hydrologic cycle, the hydrometeorological parameter of evapotranspiration (ET), is critical in the development of effective water resources planning and irrigation scheduling. The ET varies in response to changes in resistance at the canopy surface $r_{c}$ and soil moisture content $\theta$, especially under water-saving irrigation (WSI) practices. Drawing on data collected by eddy covariance in WSI rice paddies in eastern China in 2015 and 2016, variations in ET were studied by calculating and analyzing hourly canopy resistance $r_{c}^{h}$ and daily canopy resistance $r_{c}^{d}$. Discrepancies were noted between true daily $\mathrm{ET}\left(\mathrm{ET}_{\mathrm{tr}}^{d}\right)$ with respect to the estimated daily ET $\left(\mathrm{ET}_{r_{c}}^{d}\right)$ at different periods [0700-1600 local time (UTC + 8)]. To estimate $\mathrm{ET}_{r_{c}}^{d}$ in the WSI rice fields, the mean $r_{c}^{h}$ value between 0900 and $1000 \mathrm{LT}$, and between 1000 and 1100 LT performed considerably better than $r_{c}^{h}$ for a single time. Seasonal estimated ET $\left(\mathrm{ET}_{r_{c}}^{s}\right)$ can be accurately calculated by interpolating $r_{c}^{d}$ at different time intervals, thereby achieving a greater correlation and consistency at 2-day intervals. Then a generalized two-segment line of $r_{c}^{d}$ variation was used to calculate $\mathrm{ET}_{r_{c}}^{s}$, achieving good results and showing that in the absence of observational data, $\mathrm{ET}_{r_{c}}^{s}$ could be easily calculated through a simplified pattern of variability. In conclusion, an ET temporal upscaling method for a WSI paddy, based on variation in $r_{c}^{h}$ and $r_{c}^{d}$ values, was optimized and is recommended for local application. Future work will focus on temporal upscaling of ET by extrapolating remote sensing instantaneous estimates to daily values.
\end{abstract}

\section{Introduction}

Showing great temporal variability, evapotranspiration (ET), a key process in the hydrological cycle, serves as an important link between underlying surface and near-surface turbulence dynamics (Kalma and Calder 1994; Kalma et al. 2008; Wang and Dickinson 2012; Jiang et al. 2016). Key to studying a wide range of ecosystems (Valentijn et al. 2006; Cleugh et al. 2007; Katerji and Rana 2006), ET must be accurately determined at different temporal scales to properly assess an ecosystem's energy balance (Liu et al. 2017) or to improve an agroecosystem's water management protocols (Kang et al. 2003;

\footnotetext{
Corresponding author: Shihong Yang, ysh7731@hhu.edu.cn
}

Mu et al. 2011). Variations in meteorological conditions and crop physiology traits result in a significant temporal variation in ET and energy balance (Farah et al. 2004; Gentine et al. 2007). Finding that ET in wheat (Triticum astivum L.) fields varied significantly across temporal scales, Gentine et al. (2007) noted that canopy coverage and soil moisture content $\theta$ were key factors in estimating daily $\mathrm{ET}\left(\mathrm{ET}^{d}\right)$ from hourly $\mathrm{ET}\left(\mathrm{ET}^{h}\right)$ data. Guo et al. (2014) suggested that net radiation strongly affected both diurnal variation in $\mathrm{ET}^{h}$ and seasonal variation in $\mathrm{ET}^{d}$, whereas vapor pressure deficit solely and strongly affected $\mathrm{ET}^{h}$. In practice, agricultural water management and hydrometeorological studies generally require ET at daily or longer time scales (Farah et al. 2004; Colaizzi et al. 2006; Tang et al. 2015). However, for 
large regions and long-term monitoring, ET measurements are labor-intensive and require a large investment in equipment, making the acquisition of accurate daily regional- or global-scale ET estimates a challenge. Remote sensing, which can cope with the spatial variability of surface characteristics, is an ideal tool for acquiring instantaneous spatial ET data at the regional scale, especially in regions with nonhomogeneous vegetation cover and a complex terrain (Verstraeten et al. 2005; Allen et al. 2007; Chowdary et al. 2009). However, as remote sensing only provides primary instantaneous estimates of ET, methods to extrapolate $\mathrm{ET}^{d}$ from instantaneous remote sensing observations are needed.

Several methods, including the evaporative fraction method, crop coefficient method, canopy resistance method, Katerji-Perrier, advection-aridity method, and daily sine function, can be used to estimate $\mathrm{ET}^{d}$, based on the assumption that the diurnal course of ET is similar to that of solar irradiance (Shuttleworth 1989; Malek et al. 1992; Zhang and Lemeur 1995; Colaizzi et al. 2006; Allen et al. 2007; Hoedjes et al. 2008; Han et al. 2011; Chen et al. 2013). Shuttleworth (1989) was the first to note that the evaporation fraction, defined as the ratio between latent heat flux and available energy ( $R_{n}-G$, where $R_{n}$ is the net radiation and $G$ is the ground heat flux), was constant over a certain period of the day in clear weather, and that the evaporation fraction at noon was close to the daily average. An ET conversion method from $\mathrm{ET}^{h}$ to $\mathrm{ET}^{d}$ was established with the evaporation fraction as an intermediate variable (Zhang and Lemeur 1995; Hoedjes et al. 2008). Allen et al. (2007) extrapolated $\mathrm{ET}^{h}$ to $\mathrm{ET}^{d}$ using the crop coefficient as an intermediate variable. With canopy resistance as the intermediate variable, $\mathrm{ET}^{d}$ was estimated based on $\mathrm{ET}^{h}$ by Liu et al. (2012) in Australia. However, these methods have different applicabilities and strengths given their different theoretical foundations and supportive research.

The canopy resistance $r_{c}$ method, involving the determination of crop-specific $r_{c}$ according to theories of energy balance and aerodynamics applied at different temporal scales, allows a rational upscaling of ET for various crops. In quantitative analysis, the $r_{c}$ value reflects the variation in canopy conditions and represents critical controls on heat and vapor flux transfer through the soil-plant-atmosphere continuum (SPAC) system within the canopy (Finnigan et al. 2003). The ET exhibits its specific variations in response to changes in $r_{c}$ at the canopy surface (Ershadi et al. 2015; Xu et al. 2017). Accordingly, studying variations in $r_{c}$ can provide insights into changes in crop ET. The variability in underlying surface and climate conditions has largely precluded the development of an apparatus or method for the direct measurement of $r_{c}$ at crop surfaces. However, $r_{c}$ can be inversed from results of latent and sensible heat fluxes, radiation balance, and some other relevant variables using the Penman-Monteith (PM) equation (Oue 2005; Katerji et al. 2011). Most studies which have employed $r_{c}$ in achieving a temporal upscaling of ET have been reported for upland crops (Rana et al. 1997; Lecina et al. 2003; Yan et al. 2015), and have played an important role in exploring temporal variability in ET. Liu et al. (2012) was the first to try to upscale daytime $\mathrm{ET}^{h}$ [1200-1300 local time (LT; UTC + 8)] to $\mathrm{ET}^{d}$, with $r_{c}$ as an intermediate variable, doing so for corn (Zea mays L.) and canola (Brassica napus L.). Yet, the specific time for $\mathrm{ET}^{h}$ measurement which works the best for daily ET estimation is different across sites due to differences in the underlying surface or microclimatic conditions.

Rice (Oryza sativa L.) is the main cereal crop cultivated in China, particularly in the middle and lower reaches of the Yangtze River, which is the largest rice belt in China (Ding et al. 2017). The area planted to rice in this region, and rice extends over roughly $20 \times 10^{6} \mathrm{ha}$, accounting for about $50 \%$ of the nation's rice cropping area (Ministry of Water Resources of China 2016). Impact assessments under different future climate scenarios show solar radiation to be gradually decreasing as is the availability of water resources for rice in south China (Tao et al. 2013; Yang et al. 2014). Seriously challenges of food security and global water scarcity are motivating regulators to adopt water-saving irrigation (WSI) practices for rice cultivation (Belder et al. 2004; Kato et al. 2011). Extensive use of WSI is the inevitable choice of agricultural development in China, and it is also an important in fulfilling rules of "water-saving priority" for water resources management in China. Meanwhile, the widespread implementation of WSI results in changes in energy interception, $\theta$, and crop growth, as well as heat and vapor flux transfer within the rice canopy (Gao et al. 2003; Castellvi et al. 2006; Linquist et al. 2015). Yet information regarding the energy balance and aerodynamics, as well as changes in $r_{c}$ in WSI rice fields, remains unclear. Accordingly, whether a method performs well or not in estimating rice $\mathrm{ET}$ should be assessed, as is the selection of the most representative time for $r_{c}^{h}$.

Therefore, the objectives of this study were 1) to explore the diurnal variation (during daytime) of $r_{c}$ for WSI rice; 2) to estimate daily $\mathrm{ET}\left(\mathrm{ET}_{r_{c}}^{d}\right)$ from $r_{c}^{h}$ as an intermediate variable; 3 ) to select an appropriate time interval for estimating seasonal ET $\left(\mathrm{ET}^{s}\right)$ based on daily canopy resistance $r_{c}^{d}$;4) to propose a generalized seasonal process of $r_{c}$ for the estimation of $\mathrm{ET}_{r_{c}}^{s}$ in rice paddies subjected to WSI practice in east China. The results will 
TABLE 1. Irrigation records in WSI rice field in 2015 and 2016.

\begin{tabular}{|c|c|c|c|c|}
\hline \multirow[b]{2}{*}{ Growth stages } & \multicolumn{2}{|r|}{2015} & \multicolumn{2}{|r|}{2016} \\
\hline & Date & Irrigation amount $(\mathrm{mm})$ & Date & Irrigation amount $(\mathrm{mm})$ \\
\hline Paddy preparation & 23 Jun & 118.0 & 28 Jun & 115 \\
\hline Regreening & - & - & $6 \mathrm{Jul}$ & 35 \\
\hline \multirow[t]{5}{*}{ Tillering } & $5 \mathrm{Jul}$ & 30.4 & $8 \mathrm{Jul}$ & 39.5 \\
\hline & $25 \mathrm{Jul}$ & 70.2 & $18 \mathrm{Jul}$ & 52.5 \\
\hline & - & - & $22 \mathrm{Jul}$ & 52 \\
\hline & - & - & $28 \mathrm{Jul}$ & 41.9 \\
\hline & - & - & 9 Aug & 45.5 \\
\hline \multirow[t]{2}{*}{ Jointing-booting } & 9 Aug & 48.1 & - & - \\
\hline & $3 \mathrm{Sep}$ & 38.6 & - & - \\
\hline Heading-flowering & $7 \mathrm{Sep}$ & 46.3 & 5 Sep & 37 \\
\hline Milk stage & $16 \mathrm{Sep}$ & 43.2 & - & - \\
\hline Full rice season & - & 394.9 & - & 418.4 \\
\hline
\end{tabular}

facilitate the application of the proposed $r_{c}$ upscaling procedure in agriculture and hydrometeorology for estimating $\mathrm{ET}^{d}$ at regional scale over WSI rice field from remote sensing data.

\section{Materials and methods}

\section{a. Site description and field management}

Field measurements were conducted during rice seasons in 2015 and 2016 at the Kunshan Irrigation and Drainage Experiment Station (latitude $31^{\circ} 15^{\prime} 15^{\prime \prime} \mathrm{N}$, longitude $120^{\circ} 57^{\prime} 43^{\prime \prime} \mathrm{E}$ ), situated in China's Tai Lake region. This area is subject to a subtropical monsoon climate bringing $1097.1 \mathrm{~mm} \mathrm{yr}^{-1}$ in precipitation and generating potential evaporation (measured by an E601 evaporation pan) of $1365.9 \mathrm{~mm} \mathrm{yr}^{-1}$. The mean daily temperature $T_{a}$ and relative humidity (RH) were $24.6^{\circ} \mathrm{C}$ and $81.5 \%$ during rice season, respectively. The volumetric saturated soil moisture $\theta_{s}$, field capacity $\theta_{f}$, and wilting point $\theta_{w}$ were $0.502,0.392$, and $0.179 \mathrm{~m}^{3} \mathrm{~m}^{-3}$, respectively. Rice seedlings, at interrow and intrarow spacings of 0.23 and $0.16 \mathrm{~m}$, respectively, were transplanted to the field on 27 June 2015 and 1 July 2016. The rice was irrigated when the soil moisture approached a threshold, according to local WSI practices. These varied according to the crop's phenological stage (Xu et al. 2012). Detailed records of irrigation events are presented in Table 1. Fertilizers and pesticides were applied to the WSI rice field according to the local farming practice.

An open-path eddy covariance (EC) system was installed at the site to measure the water and heat fluxes over flat rice fields with a fetch of about $200 \mathrm{~m}$ in all directions. Rice is the unique crop at the station, and is short and of consistent height. The EC system, which was aligned perpendicular to the prevailing southeast wind direction, was made up of a CSAT3A sonic anemometer (Campbell Scientific Inc., United States) and an EC150 open-path infrared gas analyzer (Campbell Scientific Inc., United States) operating at a frequency of $10 \mathrm{~Hz}$, both installed $2.5 \mathrm{~m}$ above the soil surface. To ensure the quality and integrity of meteorological data, an EC system and an automatic meteorological station (WS-STD1, DELTA-T, United Kingdom) were employed to measure net radiation $R_{n}$, air temperature $T_{a}$, wind speed $u$, atmospheric pressure $P_{a}$, precipitation $P$, soil heat flux $G_{s}$, volumetric $\theta$, and soil temperature $T_{s}$ (measured at depths of $0.10,0.20$, and $0.30 \mathrm{~m}$ ).

To trigger irrigation, the $\theta$ of the $0-0.20-\mathrm{m}$ soil layer was measured daily (when soil was not flooded) at 0800 LT, using time domain reflectometry (TDR; Trase system, Soil Moisture Equipment, United States) and buried waveguides. The soil saturation level $\theta_{r}$ (as the ratio of $\theta$ and $\theta_{s}$ ), water depth $\Delta d$, and wetting-drying cycles, as influenced by irrigation and precipitation events in WSI fields in 2015 and 2016, are depicted in Fig. 1. Canopy height $h$ and leaf area index (LAI) were measured for 20 specific plants at 5-day intervals. Daily $h$ and LAI were determined by linear interpolation (Fig. 2).

Rice ET at canopy and field scales were measured independently by weighing microlysimeters $\left(\mathrm{ET}_{\mathrm{ML}}\right)$ and $\mathrm{EC}$ system $\left(\mathrm{ET}_{\mathrm{EC}}\right)$. Three weighing microlysimeters were installed in the WSI rice field, and used to measure hourly $\mathrm{ET}_{\mathrm{ML}}\left(\mathrm{ET}_{\mathrm{ML}}^{h}\right)$ based on the hourly mass change. The configuration and location of the lysimeters and the method of $\mathrm{ET}_{\mathrm{ML}}$ measurement were described in greater detail in Liu et al. (2018a). In our previous work, slight differences were found in both amplitude and phase between $\mathrm{ET}_{\mathrm{ML}}$ and $\mathrm{ET}_{\mathrm{EC}}$ because of a spatial scale effect (Liu et al. 2018a). A relationship was developed between measured $\mathrm{ET}_{\mathrm{ML}}$ and $\mathrm{ET}_{\mathrm{EC}}$ values, such that field scale ET could be calculated from ET 

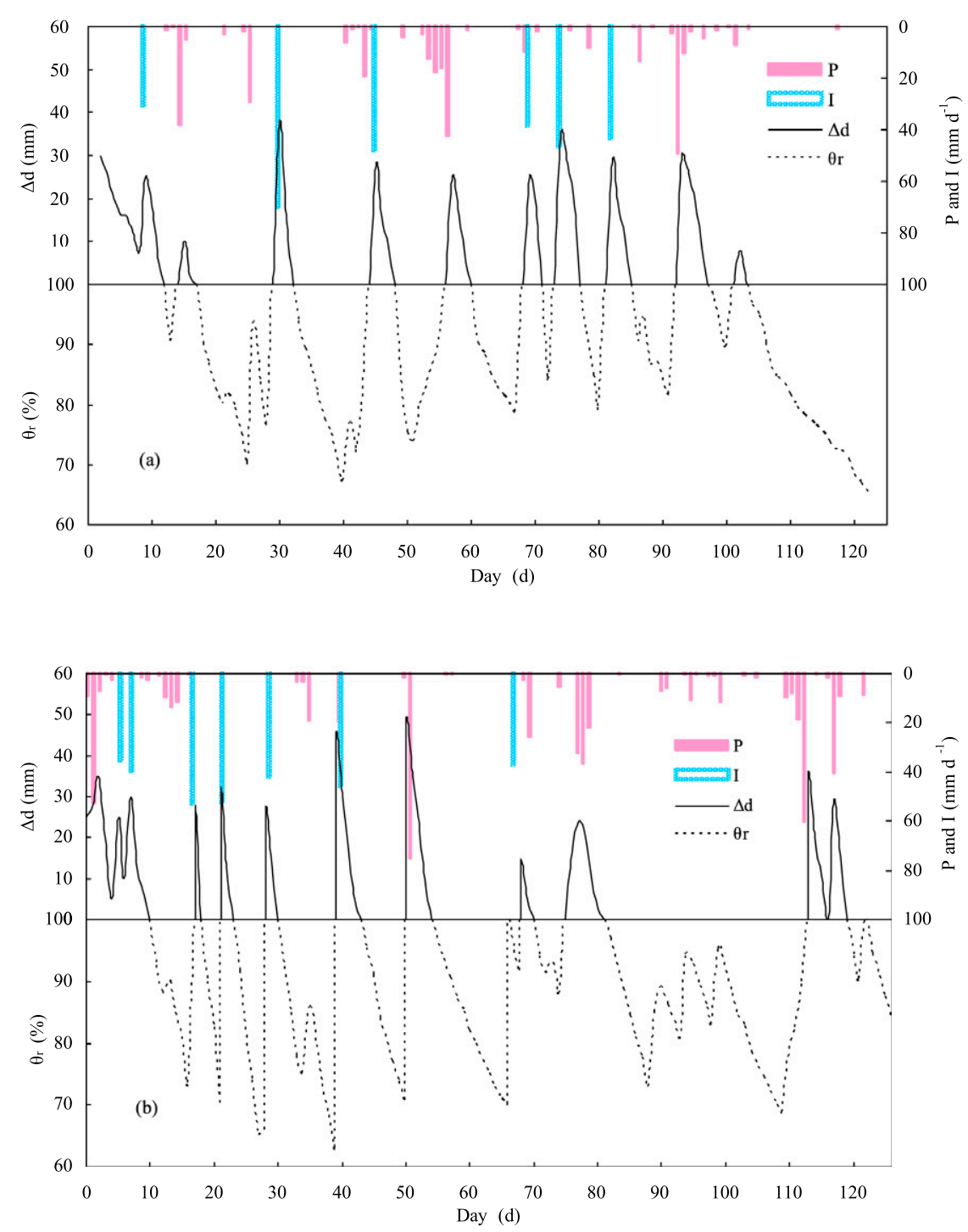

FIG. 1. Variation of soil moisture conditions and corresponding precipitation $P$ and irrigation $I$ under water-saving irrigation during the rice cropping seasons of (a) 2015 and (b) 2016 ( $\theta_{r}$ and $\Delta d$ represent soil saturation level and water depth, respectively).

measured at the canopy scale, and termed $\mathrm{ET}_{\text {tr }}$ in the present study. In conclusion, measured $\mathrm{ET}_{\mathrm{EC}}$ values served to compute canopy resistance by the PM equation, and the $\mathrm{ET}_{\mathrm{tr}}$ calculated from measured $\mathrm{ET}_{\mathrm{ML}}$ values were used as the true ET, compared with the estimated value, to evaluate the performance of the ET upscaling method.

\section{b. Data analysis and quality control of the EC system}

For the data quality control of the EC measurement, raw data $(10 \mathrm{~Hz})$ were processed by EdiRe, and necessary corrections (e.g., coordinate rotation via $2 \mathrm{D}$ rotation, sonic virtual temperature conversion for sensible heat flux, density fluctuation correction for latent heat flux, spectral loss correction, and spike detection) were implemented following procedures outlined in the literature (Anthoni et al. 2004; Mauder et al. 2006; Ueyama et al. 2012; Masseroni et al. 2013). Flux data were averaged in 30-min blocks. The prevailing wind in the rice growing season is a southeast trade. The source area was estimated based on procedures and parameters selected based on the results of Kljun et al. (2004), along with atmospheric conditions and wind directions (Aubinet et al. 2012). Fluxes were discarded when the calculated footprint was beyond the edge of the study area of WSI paddy field (Masseroni et al. 2012). When the observations exceeded the mean value by more than threefold the standard deviation, it was labeled a 

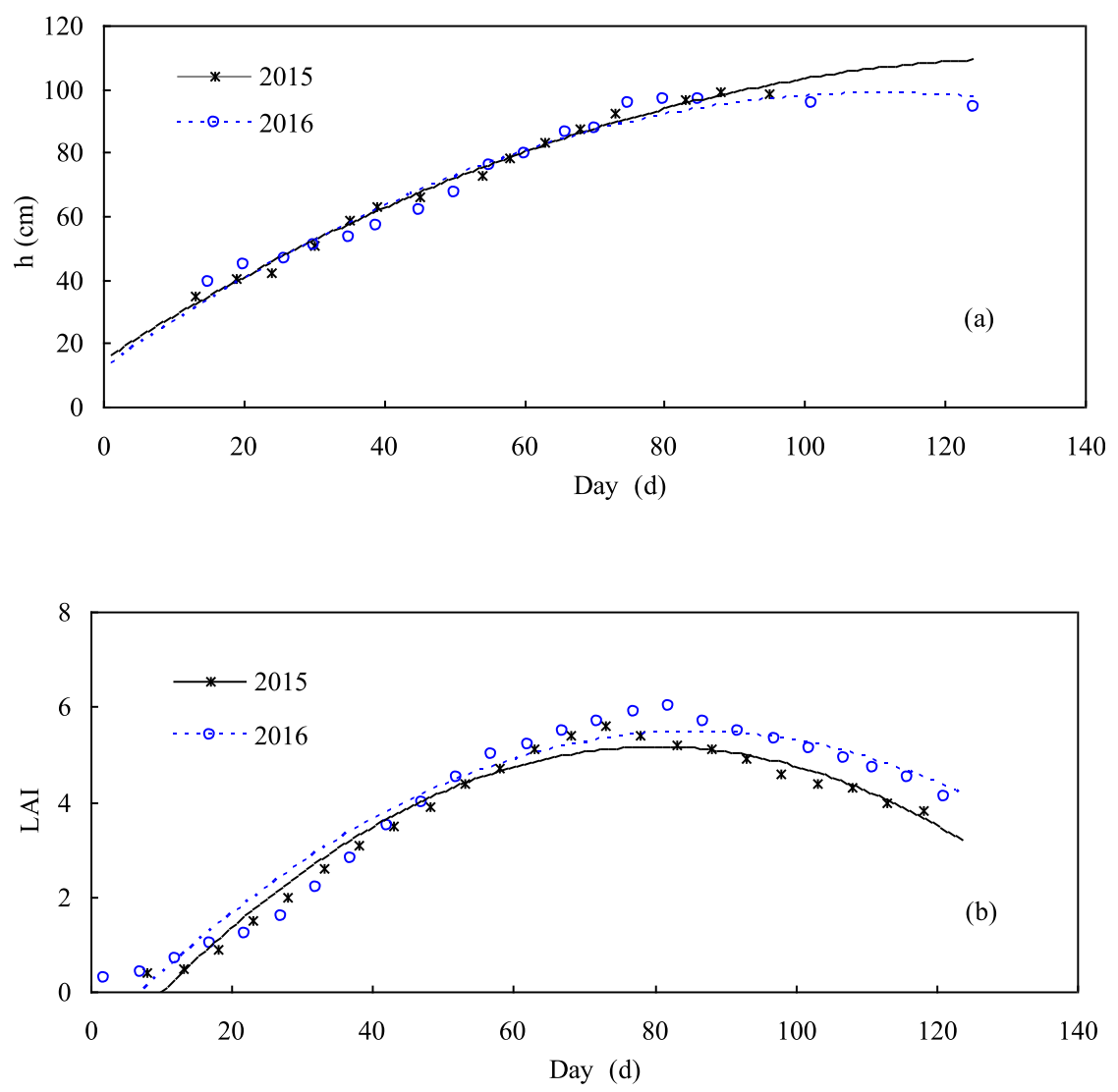

FIG. 2. Variation of (a) canopy height $h$ and (b) leaf area index (LAI) under water-saving irrigation in rice, for the 2015 and 2016 seasons.

spike (Falge et al. 2001a). Likewise, values measured during or within one hour before or after precipitation events were excluded (Anderson and Wang 2014). Flux data were filtered when the friction velocity $u^{*}$ was lower than a threshold of $0.1 \mathrm{~m} \mathrm{~s}^{-1}$ (Anthoni et al. 2004). Finally, the missing flux date, accounting for approximately $22 \%$ over the whole rice season from 2015 to 2016, were determined by linear interpolation (for lacunae $\leq 3 \mathrm{~h}$ ) or, for long data gaps, by a mean diurnal average method within a 10-day window (Falge et al. 2001b).

To improve the energy balance for EC measurement in the rice field, surface soil heat flux $G_{0}$ was calculated based on $G_{s}$-measured by heat flux plates buried at a depth of $0.08 \mathrm{~m}$-by integrating the soil heat storage $Q$ in soil above the soil heat flux plate, calculated on the basis of soil temperature and moisture data (Meyers and Hollinger 2004; Liu et al. 2017). The daily energy balance ratio (EBR), calculated by using the corrected fluxes, averaged 0.93 and 0.85 in the 2015 and 2016 rice seasons, respectively. Any energy gap is entirely related to the underestimation of sensible and latent heat fluxes (Wilson et al. 2002;
Foken 2008; Foken et al. 2011). The energy balance was closed through the evaporative fraction (EF) method (Gebler et al. 2015). The estimated EF values during the 2015 and 2016 rice cultivation seasons are shown in Fig. 3. Then, after the energy balance closure correction, the latent flux (LE) assessed over 30-min intervals and then used to calculate rice ET (Chávez et al. 2009; Gebler et al. 2015).

\section{c. Method for temporal upscaling}

\section{1) Hourly-TO-DAILY UPSCALING}

To estimate the $\mathrm{ET}_{r_{c}}^{d}$ based on field measurement at a specific hour, with $r_{c}^{h}$ as an intermediate variable, Eq. (1) was used to calculate the daytime hourly $r_{c}^{h}$ for 0700-0800, 0800-0900, 0900-1000, 1000-1100, 1100-1200, 1200-1300, 1300-1400, 1400-1500, and 1500-1600 LT $(\mathrm{UTC}+8)$ based on hourly $\mathrm{ET}_{\mathrm{EC}}$ and meteorological variables. Then, the hourly $\mathrm{ET}_{\mathrm{EC}}^{h}$ measurement at each specific hour was extended to a daily scale through the canopy resistance method, using daily meteorological data [Eq. (2)] (Malek et al. 1992; Liu et al. 2011): 


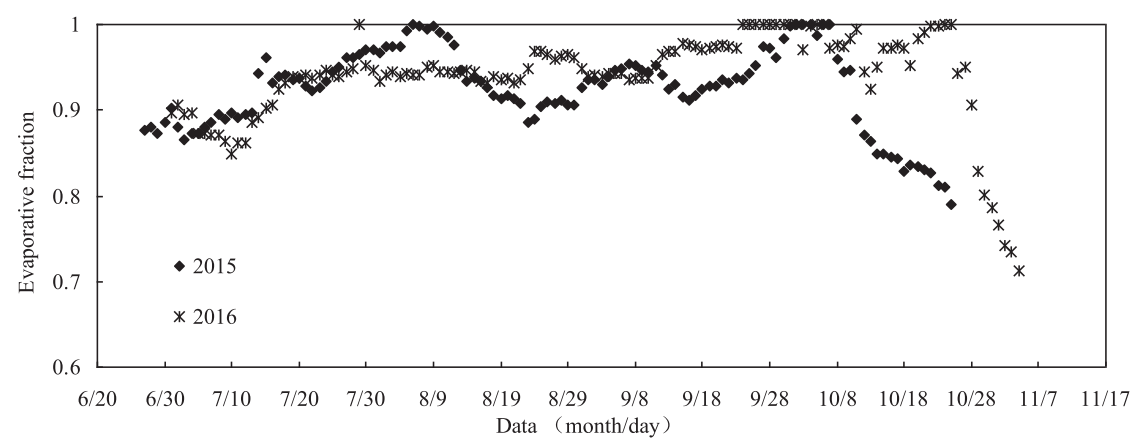

FIG. 3. Variation of evaporative fraction (EF) under water-saving irrigation in the 2015 and 2016 rice seasons.

$$
\begin{array}{r}
r_{c}^{h}=\frac{r_{a}^{h}\left[\frac{\Delta^{h}\left(R_{n}^{h}-G_{0}^{h}\right)+\rho^{h} C_{p}\left(e_{s}^{h}-e_{a}^{h}\right)}{r_{c}^{h}-\lambda^{h} \mathrm{ET}_{\mathrm{EC}}^{h}\left(\Delta^{h}+\gamma^{h}\right)}\right]}{\gamma^{h} \lambda^{h} \mathrm{ET}_{\mathrm{EC}}^{h}}, \\
\lambda^{d} \mathrm{ET}_{r_{c}}^{d}=\frac{\frac{\Delta^{d}\left(R_{n}^{d}-G_{0}^{d}\right)+\rho^{d} C_{p}\left(e_{s}^{d}-e_{a}^{d}\right)}{r_{a}^{d}}}{\Delta^{d}+\gamma^{d}\left(1+\frac{r_{c}^{h}}{r_{c}^{d}}\right)},
\end{array}
$$

where $d$ and $h$ as superscripted letters indicate the parameter's daily- and hourly-averaged values, respectively; $e_{a}$ is the actual vapor pressure $(\mathrm{kPa}) ; e_{\mathrm{s}}$ is the saturation and vapor pressure $(\mathrm{kPa})$, where $e_{\mathrm{s}}-e_{a}$ is the vapor pressure deficit (VPD); $r_{a}$ is the aerodynamic resistance of water vapor transfer from the surface to ambient air $\left(\mathrm{s} \mathrm{m}^{-1}\right) ; r_{c}$ is the canopy resistance of water vapor transfer from the surface to ambient air $\left(\mathrm{s} \mathrm{m}^{-1}\right)$; $C_{p}$ is the specific heat capacity of air, $C_{p}=1.013 \times$ $10^{-3} \mathrm{MJ} \mathrm{kg}^{-1}{ }^{\circ} \mathrm{C}^{-1} ; \mathrm{ET}_{\mathrm{EC}}$ is the evapotranspiration measured by systems (mm); $\mathrm{ET}_{\mathrm{ML}}$ is the evapotranspiration measured by microlysimeters $(\mathrm{mm}) ; \mathrm{ET}_{r_{c}}^{d}$ is the daily evapotranspiration ( $\mathrm{mm}$ ) estimated by upscaling; $G_{0}$ is surface soil heat flux $\left(\mathrm{MJ} \mathrm{m}^{-2} \mathrm{~s}^{-1}\right)$, where $G_{0}=$ $G_{s}+Q$, with $G_{s}$ being the soil heat flux measured at $0.80 \mathrm{~m}$ beneath the soil surface and $Q$ being the change in soil heat storage in the $0-0.80-\mathrm{m}$ surface soil layer; $P$ is the atmospheric pressure $(\mathrm{kPa}) ; R_{n}$ is net radiation $\left(\mathrm{MJ} \mathrm{m}^{-2} \mathrm{~s}^{-1}\right) ; T_{a}$ is the average temperature $\left({ }^{\circ} \mathrm{C}\right) ; \gamma$ is the psychometric constant $\left(\mathrm{kPa}^{\circ} \mathrm{C}^{-1}\right), \gamma=0.00163 \mathrm{P} / \lambda$; $\lambda$ is the latent flux of heat $\left(\mathrm{MJ} \mathrm{kg}^{-1}\right), \lambda=2.501-$ $\left(2.361 \times 10^{-3}\right) T_{a} ; \rho$ is the density of dry air $\left(\mathrm{kg} \mathrm{m}^{-3}\right)$; and $\Delta$ is the slope of the saturation-to-vapor pressure curve $\left(\mathrm{kPa}{ }^{\circ} \mathrm{C}^{-1}\right)$.

Assuming that samples passing quality control were generally near neutral atmospheric stability, the aerodynamic resistance $r_{a}$ is calculated at either an hourly $r_{a}^{h}$ or daily $r_{a}^{d}$ time scale, based on hourly or daily average wind speeds [Eq. (3)] (Alves et al. 1998):

$$
r_{a}=\frac{\ln \frac{z_{m}-d}{z_{0 m}} \ln \frac{z_{h}-d}{z_{0 h}}}{k^{2} u}
$$

where $d$ is zero-plane displacement height (m), with $d=$ $0.63 h ; h$ is the rice canopy height $(\mathrm{m}) ; k$ is von Kármán's constant (0.41); $u$ is wind speed at $2.5 \mathrm{~m}$ above the soil surface $\left(\mathrm{m} \mathrm{s}^{-1}\right) ; z_{h}$ is the height of relative humidity measurements (m); $z_{m}$ is the height of wind measurements $(2.5 \mathrm{~m}$ in the EC system); $z_{0 h}$ is the roughness length governing transfer of heat and vapor $(\mathrm{m}), z_{0 h}=0.1 z_{0 m}$; and $z_{0 m}$ is roughness length governing momentum transfer $(\mathrm{m}), z_{0 \mathrm{~m}}=0.123 \mathrm{~h}$.

\section{2) The DAILy-TO-SEASOnAl upsCALING}

In both 2015 and 2016, Eq. (4) was used to calculate the $r_{c}^{d}$ at sparse specific days based on $\mathrm{ET}_{r_{c}}^{d}$ measured by EC $\left(\mathrm{ET}_{\mathrm{EC}}^{d}\right)$ after energy balance correction, along with meteorological variables of rice growth period. For days without $\mathrm{ET}_{\mathrm{EC}}^{d}$ measurements, $r_{c}^{d}$ was calculated by linear interpolation between two adjacent known values of $r_{c}^{d}$, prior to $\mathrm{ET}_{r_{c}}^{d}$ being calculated according to $r_{c}^{d}$ and daily meteorological data. Assuming $\mathrm{ET}_{\mathrm{EC}}^{d}$ to be measured at intervals of 2, 5, 10, 15 , and 20 days, $r_{c}^{d}$ values on these days were calculated first, and then for days without $\mathrm{ET}_{\mathrm{EC}}^{d}$ measurement $r_{c}^{d}$ values were interpolated. In the end, $\mathrm{ET}_{r_{c}}^{d}$ values over the full rice growing season were estimated and averaged as seasonal average daily ET (ET $\mathrm{EC}_{\mathrm{E}}^{\text {) }}$ by Eq. (5) (Malek et al. 1992; Liu et al. 2011):

$$
\begin{gathered}
r_{c}^{d}=\frac{\frac{r_{a}^{d}\left[\Delta^{d}\left(R_{n}^{d}-G_{0}^{d}\right)+\rho^{d} C_{p}\left(e_{s}^{d}-e_{a}^{d}\right)\right]}{r_{a}^{d}-\lambda^{d} \mathrm{ET}_{\mathrm{EC}}^{d}\left(\Delta^{d}+\gamma^{d}\right)}}{\gamma^{d} \lambda^{d} \mathrm{ET}_{\mathrm{EC}}^{d}} \\
\mathrm{ET}_{r_{c}}^{s}=\frac{1}{\lambda^{d} m} \sum_{k=1}^{k=m}\left[\frac{\frac{\Delta_{k}^{d}\left(R_{n_{k}}^{d}-G_{0_{k}}^{d}\right)+\rho_{k}^{d} C_{p_{k}}\left(e_{s_{k}}^{d}-e_{a_{k}}^{d}\right)}{r_{a_{k}}^{d}}}{\Delta_{k}^{d}+\gamma_{k}^{d}\left(1+\frac{r_{c_{k}}^{d}}{r_{a_{k}}^{d}}\right)}\right],
\end{gathered}
$$


where $k$ represents the day of the season; $m$ is the total number of days in the season; $s$ and $h$ superscripted letters indicate the parameter's seasonal- and daily averaged values, respectively; and $\mathrm{ET}_{r_{c}}^{s}$ is the calculated seasonal average daily value during the rice growing season $\left(\mathrm{mm} \mathrm{day}^{-1}\right)$.

\section{d. Statistical analysis}

The $\mathrm{ET}_{\mathrm{tr}}$ calculated from the measured $\mathrm{ET}_{\mathrm{ML}}$ values were used as the true ET, to compare with estimated upscaling value. Linear regression slope, coefficient of determination $\left(R^{2}\right)$, root-mean-square error (RMSE), and index of agreement (IOA) were used to assess the performance of the temporal upscaling method, and reveal the agreement between the estimated and true ET:

$$
\begin{aligned}
R^{2} & =\left[\frac{\sum_{i=1}^{i=n}\left(O_{i}-\bar{O}\right)\left(P_{i}-\bar{P}\right)}{\sqrt{\sum_{i=1}^{i=n}\left(O_{i}-\bar{O}\right)^{2} \sum_{i=1}^{i=n}\left(P_{i}-\bar{P}\right)^{2}}}\right]^{2}, \\
\mathrm{RMSE} & =\sqrt{\frac{\sum_{i=1}^{i=n}\left(P_{i}-O_{i}\right)^{2}}{N},} \\
\mathrm{IOA} & =1-\frac{\sum_{i=1}^{i=n}\left(P_{i}-O_{i}\right)^{2}}{\sum_{i=1}^{i=n}\left(\left|P_{i}-\bar{O}\right|+\left|O_{i}-\bar{O}\right|\right)^{2}},
\end{aligned}
$$

where $n$ is the number of samples; $P_{i}$ and $O_{i}$ are the $i$ th estimated and true values, respectively, where $i=1,2$, $3, \ldots, n$; and $\bar{P}$ and $\bar{O}$ are the mean estimated and true values, respectively.

\section{Results and discussion}

\section{a. Daily ET (ET $\left.T_{r_{c}}^{d}\right)$ estimated based on hourly canopy resistance $r_{c}$}

\section{1) VARIATION IN HOURLY CANOPY RESISTANCE $\left(r_{c}^{h}\right)$ DURING DAYTIME}

Diurnal variation of mean $r_{c}^{h}$ in rice season is shown in Fig. 4. In the morning (0700-0800 LT), $r_{c}^{h}$ was negative, and then increased gradually to be positive during 0800 $0900 \mathrm{LT}$. Then, $r_{c}^{h}$ was almost constant from 0900 to 1200 LT, before a slight decrease between 1200 and $1300 \mathrm{LT}$. This is owing to increased stomatal conductance at noon when the light is strongest (Alves et al. 1998; Allen et al. 2006). After this, $r_{c}^{h}$ tended to increase rapidly, more than $150 \mathrm{~s} \mathrm{~m}^{-1}$ at $1500-1600 \mathrm{LT}$ both in 2015 and 2016. Theoretically, canopy resistance should

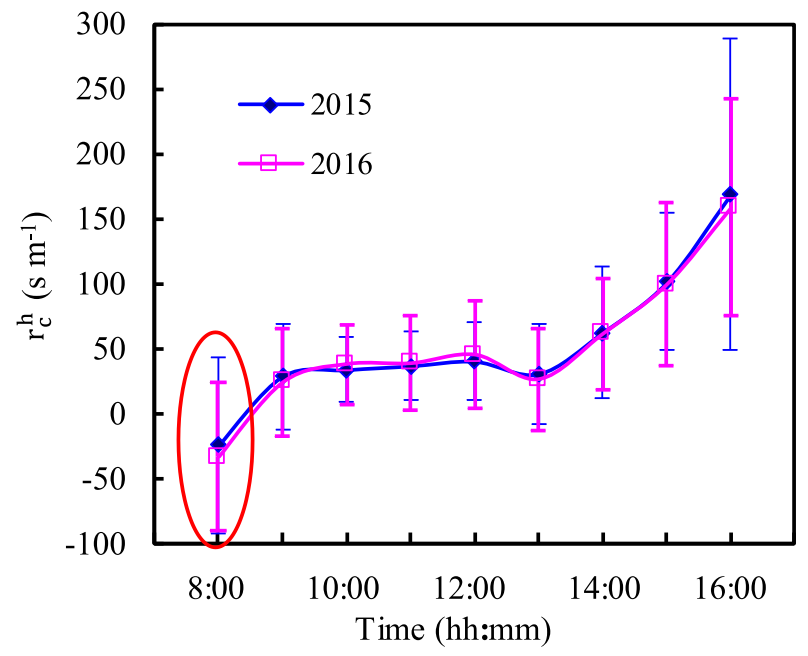

FIG. 4. Diurnal variation in average hourly canopy resistance $r_{c}^{h}$ during daytime in the 2015 and 2016 rice seasons. Note: 1) The abscissa in the figure at the label 8:00 represents the eigenvalue of the period 0700-0800 LT, and so on. 2) The result of $<0$ during the period of 0700-0800 LT is an artificial effect of the algorithm, making no physical nor physiological sense. 3) Error bars represent the standard error of the mean.

be high in the morning and evening, due to the lower light intensity and leaf stomatal conductance. However, the $r_{c}^{h}$ in the morning was extremely low (even less than zero prior to $0800 \mathrm{LT}$ ), and the average $r_{c}^{h}$ was $35 \mathrm{~s} \mathrm{~m}^{-1}$ with little variation during morning hours (0900-1200 LT). A result of $r_{c}<0$ in current study (circled in red in Fig. 4) is the result of inversion by the PM equation, which is an artificial effect of the algorithm. Specifically, vapor condensation occurred in early morning within the rice field when the air humidity was high, especially before sunrise (generally RH higher than 95\%) (Malek et al. 1999; Kabela et al. 2009; Hanisch et al. 2015; Liu et al. 2018b). Meanwhile, the soil hygroscopic water (during the nonflooding period in WSI rice paddy) was easy to produce in which the air humidity was high, and it accumulated prior to sunrise (Verhoef et al. 2006; Zhang et al. 2015). That favored the process of evapotranspiration over a short period after sunrise. As a result, the measured actual ET increased, and the $r_{c}^{h}$, inversed from actual hourly ET by the PM equation is extremely low. Similar results were reported by Malek et al. (1992), Allen et al. (2006), and Perez et al. (2006), who found that $r_{c}^{h}$ was negative or had no defined value in the early morning. Thus, canopy resistance inversed by the PM equation should be treated seriously and cannot be derived simply when dew formation occurs or when leaves are covered with dew.

It should also be noted that $r_{c}^{h}$ tended to increase, with high values in the afternoon. This phenomenon is partially ascribed to the hourly time course of the environmental variables in the afternoon. The values of $r_{c}^{h}$, which were influenced by climatic factors, increased 

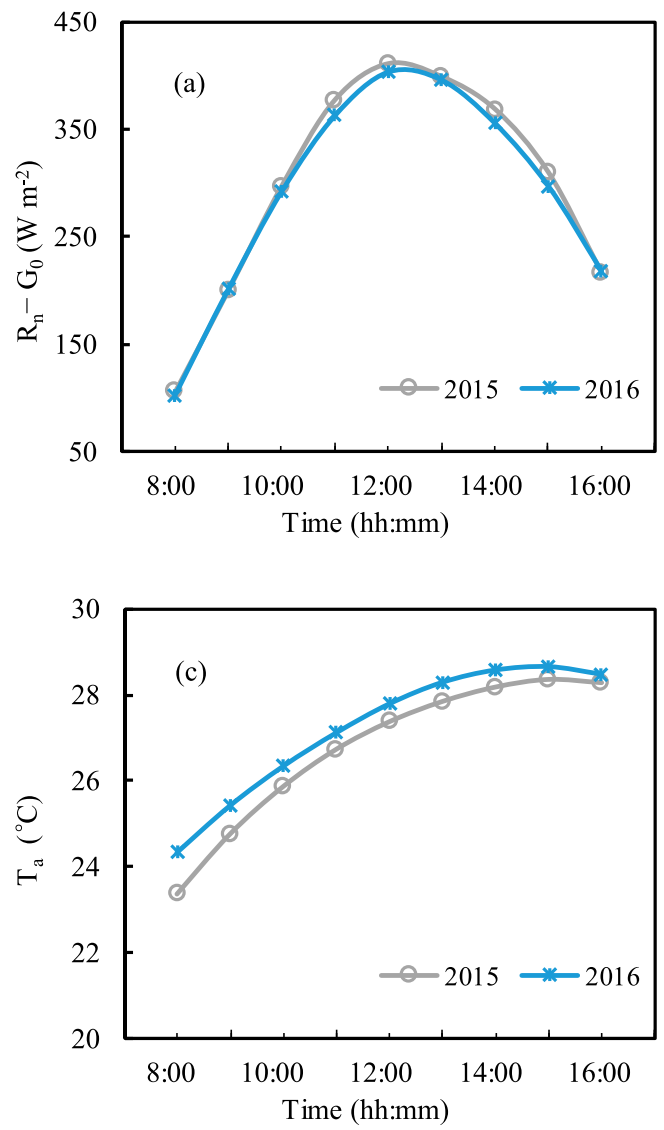

drastically after $1300 \mathrm{LT}$, showing an opposite variation to $R_{n}-G_{0}$ and a similar variation to $T_{a}$ or VPD (Fig. 5). In fact, canopy resistance is subject to the variation in $R_{n}-G_{0}$ (or $R_{n}$ ) in two ways: (i) crop stomatal conductance decreases with a decrease in radiation intensity; and (ii) as the source of energy for evaporation and transportation in the field energy balance, a decrease in $R_{n}-G_{0}$ tends to result in low $r_{c}^{h}$ in the afternoon. Clearly, canopy resistance also depends highly on VPD (Fig. 5). When the VPD increases, i.e., $T_{a}$ increases while the air humidity decreases, the air water potential is lower than the leaf water potential, resulting in the increase of water loss by transpiration and the decline in leaf water potential. With the decrease of the leaf-air water potential difference, the transpiration rate is limited and the canopy temperature increases, which causes a relatively high $r_{c}^{h}$ in later afternoons. The increase tendency in rice $r_{c}^{h}$ in the afternoon agrees well with results on grass, either in semiarid or Mediterranean climates, that showed that hourly canopy resistance increased in the afternoon in an irregular parabolic pattern (Todorovic 1999; Lecina et al. 2003; Allen et al. 2006; Perez et al. 2006). Results on upland crops (soybean or winter wheat) whose canopy resistance increased in the afternoon with

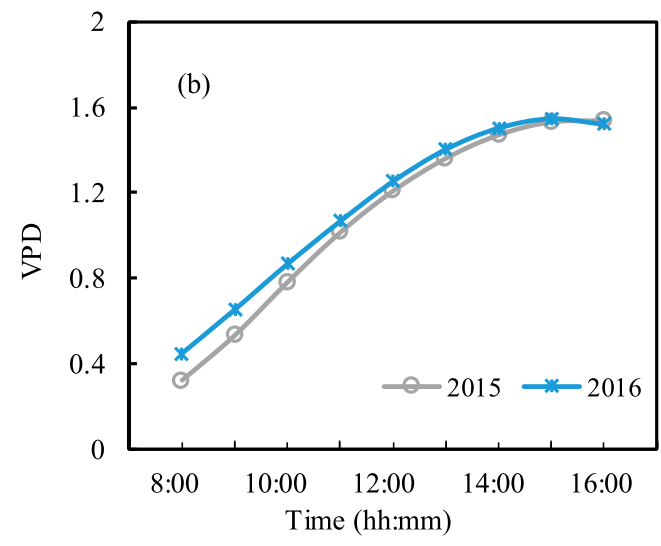

FIG. 5. The diurnal variation of average hourly (a) available energy $\left(R_{n}-G_{0}\right)$, (b) vapor pressure deficit (VPD), and (c) air temperature $T_{a}$ during daytime in the 2015 and 2016 rice seasons.

the largest increment occurring during sunset (Bailey and Davies 1981; Hu et al. 2005).

\section{2) Estimating $\mathrm{ET}_{r_{c}}^{d}$ FROM $r_{c}^{h}$ AT A SPECIFIC TIME}

Daily simulated rice $\mathrm{ET}$ (i.e., $\mathrm{ET}_{r_{c}}^{d}$ ), was calculated from daily meteorological data and $r_{c}^{h}$ at different daytime hours [Eq. (2)]. Performance of $\mathrm{ET}_{r_{c}}^{d}$ calculations against the true $\mathrm{ET}_{\mathrm{tr}}^{d}$ in the 2015 and 2016 rice season is shown in Fig. 6. For $\mathrm{ET}_{\mathrm{EC}}^{d}$ estimated from $r_{c}^{h}$ at specific times from 0700 to $1600 \mathrm{LT}$, the regression slope between $\mathrm{ET}_{r_{c}}^{d}$ and $\mathrm{ET}_{\mathrm{tr}}^{d}$ decreased gradually, with the maximum values of 1.201 and 1.189 at $0700-0800 \mathrm{LT}$ in 2015 and 2016, and minimum values of 0.805 and 0.851 at 1500-1600 LT, respectively. Correspondingly, $\mathrm{ET}_{r_{c}}^{d}$ calculated based on $r_{c}^{h}$ at different hours reduced gradually from values greater than the true $\mathrm{ET}_{\text {tr }}^{d}$ to values inferior to it, i.e., from 4.801 to $3.118 \mathrm{~mm}$ day $^{-1}$ in $2015\left(\mathrm{ET}_{\mathrm{tr}}^{d}=3.835 \mathrm{~mm} \mathrm{day}^{-1}\right)$, and from 4.671 to $3.299 \mathrm{~mm} \mathrm{day}^{-1}$ in $2016\left(\mathrm{ET}_{\mathrm{tr}}^{d}=3.816 \mathrm{~mm} \mathrm{day}^{-1}\right)$. The error of the estimated $\mathrm{ET}_{r_{c}}^{d}$ was large when it was calculated with $r_{c}^{h}$ at sunset or sunrise (Fig. 6). The $\mathrm{ET}_{r_{c}}^{d}$, estimated with $r_{c}^{h}$ from 0900 to $1000 \mathrm{LT}$ or 1000 to $1100 \mathrm{LT}$, matched well with $\mathrm{ET}_{\mathrm{tr}}^{d}$. The correlations between $\mathrm{ET}_{r_{c}}^{d}$ and $\mathrm{ET}_{\mathrm{tr}}^{d}$ were the best in those periods, 

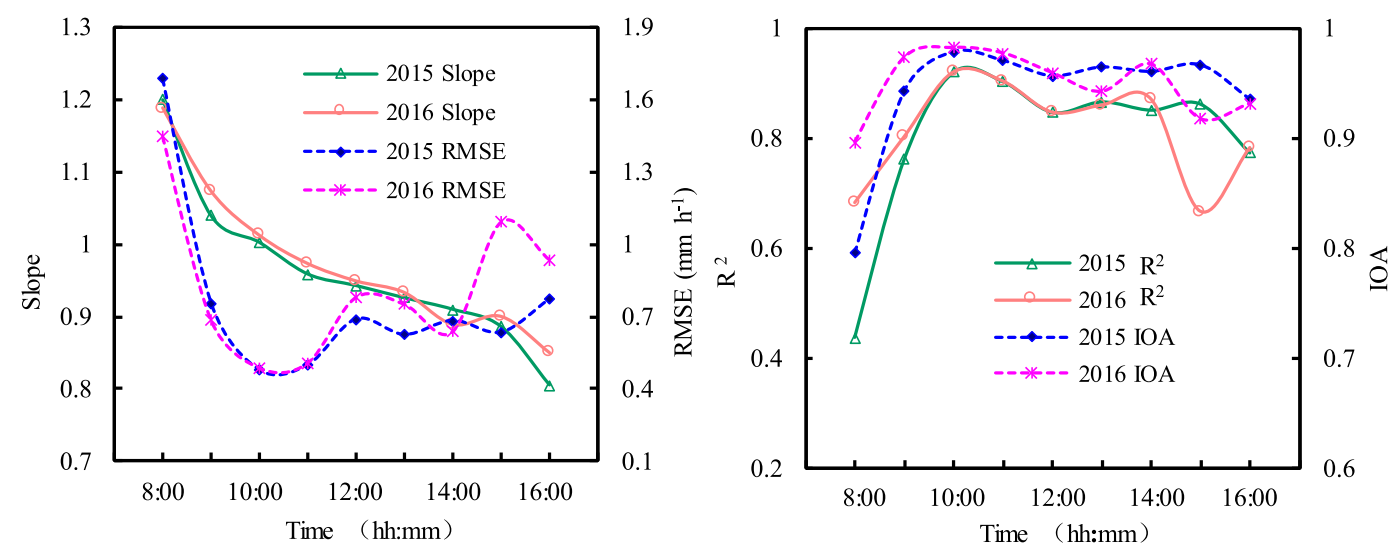

FIG. 6. Average diurnal variation in model performance based on statistical indexes (slope, RMSE, $R^{2}$, and IOA) for ET estimation during daytime in the 2015 and 2016 rice seasons.

with high $R^{2}(>0.90)$ and IOA $(>0.97)$, and low $\operatorname{RMSE}\left(<0.51 \mathrm{~mm} \mathrm{~h}^{-1}\right)$.

The reason these two hours provide the best estimation may be related to the neutral stability assumption for the atmospheric boundary layer. In several current studies on $r_{a}$ model implementation, neutral atmospheric stability conditions have been assumed rather than actual stability conditions (Brunet et al. 1994; Anadranistakis et al. 2000; Patton et al. 2016). Results showed that an acceptable accuracy in ET estimation was achieved when it was estimated at weekly or longer intervals or scale (Anadranistakis et al. 1999). This suggests that the assumption of neutral stability was easily satisfied. However, when ET was estimated on a short time scale (intraday variation), the actual atmospheric stability conditions should be taken into account (Dupont and Patton 2012; Liu et al. 2015), although some studies have shown that it is feasible to neglect the correction of atmospheric stability in calculating crop ET (Van Zyl and De Jager 1987; Zhou et al. 1994).

The frequency of atmospheric stability (neutral stability, stable and unstable situations) are generally associated with diurnal variation. Stable conditions mainly occur at night, while unstable conditions may dominate around noon. From night to daytime, the atmospheric stability varies from stable to unstable, and the occurrence of neutral stability conditions are observed to be dominant in the morning (0900-1100 LT) and afternoon (1400-1600 LT). During other periods, the boundary layer is often either unstable or stable, which violates the neutral stability assumption, and consequently the equation of $r_{a}$ is invalid. In addition, considering the tendency in $r_{c}^{h}$ variation is smallest from 0900 to $1100 \mathrm{LT}$, it is preferred for temporally upscaling rice ET from hourly to daily.

\section{3) IMPROVING THE PERFORMANCE IN $\mathrm{ET}_{r_{c}}^{d}$ ESTIMATION}

According to the results in Fig. 6 and Table 2, the $\mathrm{ET}_{r_{c}}^{d}$ estimated based on $r_{c}^{h}$ during $0900-1000$ LT or 1000$1100 \mathrm{LT}$ matched $\mathrm{ET}_{\mathrm{tr}}^{d}$ well, compared with other specific hours. Furthermore, the average value of $r_{c}^{h}$ during 0900-1000 LT and 1000-1100 LT performed much better in $\mathrm{ET}_{r_{c}}^{d}$ estimation than the $r_{c}^{h}$ from a single hour (either 0900-1000 LT or 1000-1100 LT) in a WSI rice field (shown in Fig. 6 and Table 2). For the 2015 dataset, the estimated $\mathrm{ET}_{r_{c}}^{d}$ was $3.789 \mathrm{~mm} \mathrm{day}^{-1}$; the RMSE was $0.422 \mathrm{~mm} \mathrm{day}^{-1}$, and the $R^{2}$ and IOA were 0.934 and 0.983 , respectively, based on $r_{c}^{h}$ averaged across the period of 0900-1100 LT. For the 2016 dataset, the calculated value was also in acceptable agreement with the true value: $R^{2}=0.945, \mathrm{RMSE}=0.431 \mathrm{~mm} \mathrm{day}^{-1}$, and $\mathrm{IOA}=0.988$. Therefore, one can improve the predictive performance of rice $\mathrm{ET}_{r_{c}}^{d}$ estimation in WSI fields by averaging the $r_{c}^{h}$ across the periods of 0900-1000 LT and 1000-1100 LT.

\section{b. Seasonal ET $\left(E T_{r_{c}}^{s}\right)$ estimated based on daily canopy resistance $\left(r_{c}^{d}\right)$}

\section{1) Seasonal Variation OF Rice $r_{c}^{d}$}

Seasonal variation of daily rice $r_{c}^{d}$ inversed by $\mathrm{ET}_{\mathrm{EC}}^{d}$ in 2015 and 2016 is shown in Fig. 7. During the first 100 days after transplantation, the value of $r_{c}^{d}$ fluctuated in a narrow range around the average value over this period (41.8 and $39.3 \mathrm{~s} \mathrm{~m}^{-1}$ in 2015 and 2016, respectively), which was much lower than the value of $70 \mathrm{~s} \mathrm{~m}^{-1}$ of a reference crop surface (Allen et al. 1989; Todorovic 1999). In the maturity period at the end of the rice season (100+ days after transplanting), $r_{c}^{d}$ increased linearly with time up to a value above $200 \mathrm{~s} \mathrm{~m}^{-1}$ when soil 
TABLE 2. Performance of the ET estimation by the canopy resistance method for a WSI rice field.

\begin{tabular}{|c|c|c|c|c|c|c|c|c|}
\hline Year & Time $(\mathrm{UTC}+8)$ & Slope & $R^{2}$ & $\begin{array}{c}\mathrm{RMSE} \\
\left(\mathrm{mm} \mathrm{d}^{-1}\right)\end{array}$ & IOA & $\begin{array}{c}r_{c}^{h} \\
\left(\mathrm{~s} \mathrm{~m}^{-1}\right)\end{array}$ & $\begin{array}{c}\mathrm{ET}_{\mathrm{tr}}^{d} \\
\left(\mathrm{~mm} \mathrm{day}^{-1}\right)\end{array}$ & $\begin{array}{c}\mathrm{ET}_{r_{c}}^{d} \\
\left(\mathrm{~mm} \mathrm{day}^{-1}\right)\end{array}$ \\
\hline \multirow[t]{10}{*}{2015} & 0700-0800 & 1.201 & 0.438 & 1.688 & 0.796 & -24.6 & 3.835 & 4.801 \\
\hline & 0800-0900 & 1.040 & 0.762 & 0.756 & 0.943 & 28.5 & & 4.118 \\
\hline & 0900-1000 & 1.003 & 0.921 & 0.477 & 0.981 & 33.4 & & 3.889 \\
\hline & $1000-1100$ & 0.959 & 0.904 & 0.498 & 0.977 & 36.4 & & 3.699 \\
\hline & $1100-1200$ & 0.943 & 0.848 & 0.689 & 0.957 & 39.9 & & 3.660 \\
\hline & $1200-1300$ & 0.926 & 0.867 & 0.624 & 0.966 & 30.3 & & 3.624 \\
\hline & $1300-1400$ & 0.910 & 0.852 & 0.683 & 0.961 & 62.2 & & 3.551 \\
\hline & $1400-1500$ & 0.886 & 0.863 & 0.634 & 0.967 & 101.0 & & 3.430 \\
\hline & $1500-1600$ & 0.805 & 0.774 & 0.772 & 0.936 & 168.6 & & 3.118 \\
\hline & 0900-1100 & 0.975 & 0.934 & 0.422 & 0.983 & 34.8 & & 3.789 \\
\hline \multirow[t]{10}{*}{2016} & 0700-0800 & 1.189 & 0.683 & 1.449 & 0.897 & -33.8 & 3.816 & 4.671 \\
\hline & 0800-0900 & 1.074 & 0.804 & 0.686 & 0.974 & 23.8 & & 4.134 \\
\hline & 0900-1000 & 1.013 & 0.923 & 0.487 & 0.985 & 37.8 & & 3.918 \\
\hline & 1000-1100 & 0.974 & 0.906 & 0.508 & 0.981 & 38.4 & & 3.726 \\
\hline & $1100-1200$ & 0.950 & 0.849 & 0.781 & 0.960 & 45.0 & & 3.657 \\
\hline & $1200-1300$ & 0.934 & 0.862 & 0.752 & 0.943 & 26.1 & & 3.740 \\
\hline & $1300-1400$ & 0.890 & 0.873 & 0.639 & 0.968 & 61.2 & & 3.529 \\
\hline & $1400-1500$ & 0.901 & 0.667 & 1.094 & 0.918 & 99.3 & & 3.578 \\
\hline & $1500-1600$ & 0.851 & 0.784 & 0.937 & 0.932 & 158.3 & & 3.299 \\
\hline & 0900-1100 & 0.993 & 0.945 & 0.431 & 0.988 & 38.1 & & 3.822 \\
\hline
\end{tabular}

moisture declined, and the rice canopy showed gradual senescence.

Notably, the variation of $r_{c}^{d}$ in a WSI rice field was different from that of grass under optimal water conditions, as well as that of upland crops. For grass, $r_{c}^{d}$ varied in a parabolic pattern, with $r_{c}^{d}$ at the beginning and end of the year being much higher than $r_{c}^{d}$ in June to July (minimum of $45 \mathrm{~s} \mathrm{~m}^{-1}$ ) (Todorovic 1999). For upland crops, lower $\theta$ and lower canopy coverage in early growth stages resulted in low evaporation and crop transpiration; consequently, the value of $r_{c}^{d}$ was relatively large (Irmak et al. 2013; Bastidas-Obando et al. 2017). However, in the WSI rice field, evaporation from the interplant (soil or water) surface was high in the early stage (regreening and early tillering stages) when the temperature and radiation were higher. The $r_{c}^{d}$, inversed by PM (characterized as a single-source "big leaf" model by which the sources of heat and water vapor from rice field were considered to occur at a single level within the canopy), was generally smaller than that of upland crops. In middle phenological stages, when rice growth was vigorous and crop ET was high, $r_{c}^{d}$ was minimal. Since the $\theta$ is much greater in a WSI rice field than in upland fields, the rice $r_{c}^{d}$ was smaller than that of upland crops and grass (Lecina et al. 2003; Jiang et al. 2016; Bastidas-Obando et al. 2017). In the rice crop's mature period, the leaves' ability to transpire weakens; meanwhile, $R_{n}$ decreases and $\theta$ is relatively low, resulting in a low ET. Accordingly, the calculated $r_{c}^{d}$ increased. The increasing tendency in the rice crop's $r_{c}^{d}$ at the mature stage was in close agreement with $r_{c}^{d}$ values for upland crops (Lecina et al. 2003; Bastidas-Obando et al. 2017).
In 2015 and 2016, on days when the field was flooded or the soil at saturation, the average $r_{c}^{d}$ values were 32.2 and $33.1 \mathrm{~s} \mathrm{~m}^{-1}$, respectively. These values were inferior to the seasonal average value for $r_{c}^{d}\left(52.3\right.$ and $50.4 \mathrm{~s} \mathrm{~m}^{-1}$ in 2015 and 2016, respectively) and much lower than the average $r_{c}^{d}$ for days without flooding water $\left(62.3\right.$ and $58.3 \mathrm{~s} \mathrm{~m}^{-1}$ in 2015 and 2016, respectively). On days without flooding water in the WSI rice field, $r_{c}^{d}$ increased with a decrease in $\theta$ from $\theta_{s}$ to $\theta_{f}$ or an even lower moisture level (Fig. 7). Similar results, where $r_{c}^{d}$ was generally low on days with sufficient soil moisture were noted in different ecosystems: e.g., agricultural crops, pastures, forest, and bare soil (McNaughton and Jarvis 1991; Zhang and Lemeur 1995).

\section{2) ESTIMATING ET $r_{c}^{s}$ BY INTERPOLATING $r_{c}^{d}$ AT DIFFERENT INTERVALS}

Based on the $\mathrm{ET}_{\mathrm{EC}}^{d}$ measured by EC at intervals of 2, $5,10,15$, and 20 days, seasonal rice evapotranspiration $\mathrm{ET}_{r_{c}}^{s}$ was estimated at these different time intervals. The calculated values were underestimated to a certain extent (approximately $0.3 \mathrm{~mm} \mathrm{day}^{-1}$ ) compared with $\mathrm{ET}_{\mathrm{tr}}^{\mathrm{s}}$ (Table 3). The regression slopes between the estimated and true values ranged between 0.892 and 0.922 . Generally, the correlations were acceptable both in 2015 and 2016, with the $R^{2}$ greater than 0.90 and 0.93 , RMSE less than 0.47 and $0.49 \mathrm{~mm} \mathrm{day}^{-1}$, and IOA up to 0.97 and 0.98 , respectively.

Theoretically, the longer the interval, the more likely it is to misrepresent the $r_{c}^{d}$ of the whole season. The correlation and consistency between the estimated and true values were higher at 2-day intervals. The accuracy 

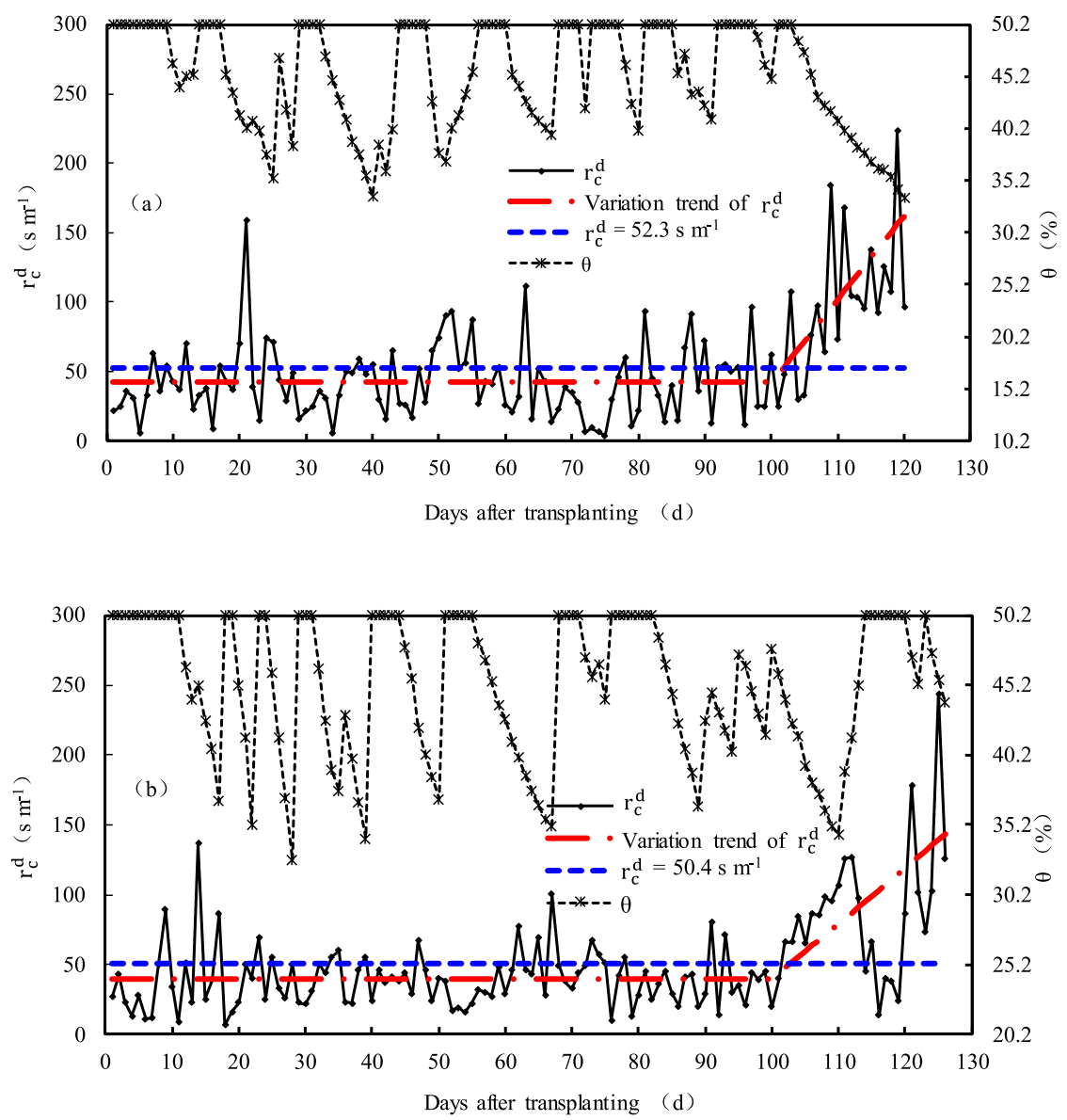

FIG. 7. Daily rice canopy resistance $r_{c}^{d}$ calculated inversely based on EC measured $\mathrm{ET}_{\mathrm{EC}}^{d}$ in (a) 2015 and (b) 2016, corresponding to variation in soil moisture conditions $\theta$.

of estimation was slightly reduced for intervals of 5,10 , 15 , and 20 days, but the difference in performance among different intervals was not clear and the simulation results were also good, because the seasonal variability pattern of $r_{c}^{d}$ was simple and consistent. Specifically, the $\mathrm{ET}_{r_{c}}^{s}$ estimated with a 20-day interval was almost the same as the result with 5-day interval, and was closer to $\mathrm{ET}_{\mathrm{tr}}^{\mathrm{s}}$ than $\mathrm{ET}_{r_{c}}^{\mathrm{s}}$ estimated with 10- or 15-day intervals with 2015 dataset.

TABLE 3. Statistics for the performance of the upscaling method over the full growth period of the rice crop.

\begin{tabular}{|c|c|c|c|c|c|c|c|c|}
\hline Year & Time interval (days) & Slope & $R^{2}$ & $\begin{array}{c}\text { RMSE } \\
\left(\mathrm{mm} \mathrm{day}^{-1}\right)\end{array}$ & IOA & $\left(\mathrm{m}^{-1} \mathrm{~s}\right)$ & $\begin{array}{c}\mathrm{ET}_{\mathrm{tr}}^{s} \\
\left(\mathrm{~mm} \mathrm{day}^{-1}\right)\end{array}$ & $\begin{array}{c}\mathrm{ET}_{r_{c}}^{s} \\
\left(\mathrm{~mm} \mathrm{day}^{-1}\right)\end{array}$ \\
\hline \multirow[t]{7}{*}{2015} & 2 & 0.905 & 0.934 & 0.415 & 0.981 & 60.5 & \multirow[t]{7}{*}{3.835} & 3.496 \\
\hline & 5 & 0.901 & 0.916 & 0.441 & 0.975 & 54.8 & & 3.508 \\
\hline & 10 & 0.901 & 0.911 & 0.470 & 0.975 & 57.5 & & 3.496 \\
\hline & 15 & 0.892 & 0.909 & 0.465 & 0.973 & 61.6 & & 3.468 \\
\hline & 20 & 0.919 & 0.913 & 0.463 & 0.976 & 44.7 & & 3.578 \\
\hline & $r_{c}^{d}=$ trend line & 0.913 & 0.910 & 0.438 & 0.974 & 52.3 & & 3.570 \\
\hline & $r_{c}^{c}=52.3 \mathrm{~s} \mathrm{~m}^{-1}$ & 0.886 & 0.907 & 0.463 & 0.972 & 52.3 & & 3.502 \\
\hline \multirow[t]{7}{*}{2016} & 2 & 0.913 & 0.938 & 0.462 & 0.983 & 55.3 & \multirow[t]{7}{*}{3.816} & 3.531 \\
\hline & 5 & 0.922 & 0.935 & 0.476 & 0.981 & 46.4 & & 3.574 \\
\hline & 10 & 0.911 & 0.936 & 0.467 & 0.982 & 58.8 & & 3.514 \\
\hline & 15 & 0.918 & 0.934 & 0.474 & 0.980 & 57.1 & & 3.535 \\
\hline & 20 & 0.904 & 0.932 & 0.485 & 0.979 & 58.9 & & 3.505 \\
\hline & $r_{c}^{d}=$ trend line & 0.915 & 0.934 & 0.468 & 0.980 & 50.4 & & 3.547 \\
\hline & $r_{c}^{c}=50.4 \mathrm{~s} \mathrm{~m}^{-1}$ & 0.891 & 0.927 & 0.486 & 0.977 & 50.4 & & 3.514 \\
\hline
\end{tabular}



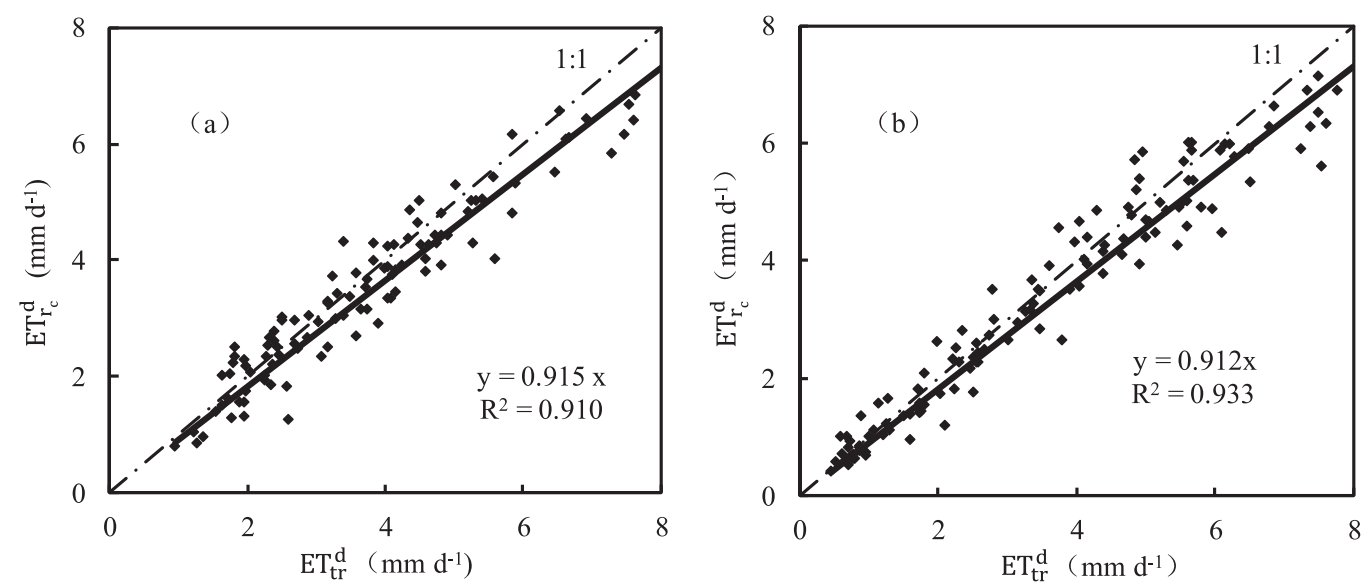

FIG. 8. Regression analysis of the simulated daily ET $\left(\mathrm{ET}_{\mathrm{tr}}^{d}\right)$ calculated based on the generalized $r_{c}^{d}$ line and true $\mathrm{ET}\left(\mathrm{ET}_{\mathrm{tr}}^{d}\right)$ in the rice seasons of (a) 2015 and (b) 2016.

Moreover, a fixed $r_{c}^{d}$ value, the seasonal average $r_{c}^{d}$ of 52.3 and $50.4 \mathrm{~s} \mathrm{~m}^{-1}$ in 2015 and 2016. respectively, was used to estimate the $\mathrm{ET}_{r_{c}}^{s}$, and the variation of $r_{c}^{d}$ was generalized as a two-segment line (red dotted line in Fig. 7) and was compared with the results from the canopy resistance method shown in Table 3. The $\mathrm{ET}_{r_{c}}^{s}$, computed from the fixed $r_{c}^{d}$ value with regression slopes of 0.886 and 0.891 in 2015 and 2016, respectively, was smaller than values estimated by the varied $r_{c}^{d}$ and the true values, although the correlation was also very good. The $\mathrm{ET}_{r_{c}}^{s}$ computed based on the generalized $r_{c}^{d}$ were more accurate and consistent, compared with some interpolation results. The $\mathrm{ET}_{r_{c}}^{s}$ values of 3.570 and $3.547 \mathrm{~mm} \mathrm{day}^{-1}$ in 2015 and 2016 , respectively, showed RMSE values of 0.438 and $0.468 \mathrm{~mm} \mathrm{day}^{-1}, R^{2}$ of 0.910 and 0.934 , and IOA of 0.974 and 0.980. In general, ET $r_{r_{c}}^{s}$ in WSI rice field can be accurately estimated by the upscaling method, which is recommended over linear interpolation for longer intervals, since its accuracy is not significantly reduced and the data inputs can be effectively reduced. Additionally, the $\mathrm{ET}_{r_{c}}^{s}$ simulation based on the generalized $r_{c}^{d}$ was also an effective and easy method when there was a lack of measured data.

\section{3) THE GENERALIZED $r_{c}^{d}$ LINE FOR ET ESTIMATION}

The overall variability pattern of $r_{c}^{d}$ was simplified as a two-segment line during the WSI rice season (Fig. 7). The two-segment line can be described as 1) constant for the first 100 days after transplanting and 2) a linear increase during the maturity stages after 100 days from transplanting. According to the local calibrated results for 2015 and 2016, the two-segment line can be expressed in Eq. (9), where $d$ represents the number of days after transplanting. This was used to calculate the $\mathrm{ET}_{r_{c}}^{s}$ in the
WSI paddy and was compared with the $\mathrm{ET}_{\mathrm{tr}}^{s}$ values in the same years, as shown in Fig. 8. For the 2015 dataset, the four accuracy indicators, slope, $R^{2}$, RMSE, and IOA had values of $0.915,0.910,0.441 \mathrm{~mm} \mathrm{~h}^{-1}$, and 0.974 , while in 2016 these values were $0.912,0.933,0.470 \mathrm{~mm} \mathrm{~h}^{-1}$, and 0.980 , respectively. The overall result was even better than the estimation through the $r_{c}$ upscaling method by linear interpolation over longer intervals $(10-, 15-$, or 20-day intervals), which indicated that the ET of WSI paddy can be calculated accurately through the simplified variability pattern of $r_{c}^{d}$ in the absence of observed data:

$$
r_{c}^{d}= \begin{cases}40.6, & d \leq 100 \\ 5 d-459.45, & 100<d \leq 120\end{cases}
$$

The linear equation [Eq. (9)] for estimating rice $r_{c}^{d}$ of is much simpler than the empirical model used for other types of vegetation (Kelliher et al. 1995; Alves and Pereira 2000; Liu et al. 2012; Yan et al. 2015). It is simple and performs well in calculating rice ET in the east China, but the constant $r_{c}$ in the first 100 days of rice growth is very hard to assess since the vegetation's canopy resistance varies with prevailing climatic conditions (OrtegaFarias et al. 2010; Zhao et al. 2015). Furthermore, if this simple equation, which is believed to be a local result, performs acceptably or not in other locations remains unknown. To plan rational irrigation, more work needs to be carried out at other sites to find generic methods of $r_{c}^{d}$ estimation with fewer measurements.

\section{Conclusions}

With canopy resistance $r_{c}$ as an intermediate variable, rice ET was upscaled temporally either from hourly to 
daily or from daily to seasonal, based on diurnal variation of hourly $r_{c}\left(r_{c}^{h}\right)$ and seasonal variation of daily $r_{c}$ $\left(r_{c}^{d}\right)$ The daily ET $\left(\mathrm{ET}_{r_{c}}^{d}\right)$ estimated with $r_{c}^{h}$ during the hours of 0900-1000 LT or 1000-1100 LT showed close agreement with the true value $\left(\mathrm{ET}_{\mathrm{tr}}^{d}\right)$. Moreover, in an WSI rice field, the average $r_{c}^{h}$ value over the periods of 0900-1000 LT and 1000-1100 LT combined performed much better in $\mathrm{ET}_{r_{c}}^{d}$ estimation than the $r_{c}^{h}$ from a single hour. For daily-to-seasonal upscaling, the $\mathrm{ET}_{r_{c}}^{s}$ calculated by interpolating $r_{c}^{d}$ at different time intervals underestimated rice ET to a certain extent compared with $\left(\mathrm{ET}_{\mathrm{tr}}^{\mathrm{s}}\right)$, with a 2-day interval offering the best performance. A generalized two-segment line can be used for depicting the seasonal variation of $r_{c}^{d}$ and estimating $\mathrm{ET}_{r_{c}}^{s}$. In conclusion, canopy resistance $\left(r_{c}\right)$ is a test competent in estimating rice ET by upscaling hourly ET to daily ET or upscaling daily ET to seasonal ET. Hourly $r_{c}$ measured during the hours of 0900-1000 LT and 1000$1100 \mathrm{LT}$ is suitable for estimating daily ET based on instantaneous estimates of ET by remote sensing. In case of sparse data availability, seasonal ET of rice can be estimated by linear interpolation the $r_{c}^{d}$, or by calculating $r_{c}^{d}$ with a simple two-segment linear equation. Future validation will be conducted to estimate rice ET with more field measurements in a greater variety of stations, or with remote sensing data.

Acknowledgments. This work was supported by the National Natural Science Foundation of China (51809075), the Natural Science Foundation of Jiangsu Province (BK20180506), the Fundamental Research Funds for the Central Universities (B200202097) and the Postdoctoral Science Foundation of China (2019M651680). The authors declare no conflict of interest.

\section{REFERENCES}

Allen, R. G., M. E. Jensen, J. L. Wright, and R. D. Burman, 1989: Operational estimates of reference evapotranspiration. Agron. J., 81, 650-662, https://doi.org/10.2134/agronj1989.00021962008100040019x.

_- M. Tasumi, and R. Trezza, 2007: Satellite-based energy balance for Mapping Evapotranspiration with Internalized Calibration (METRIC)-Model. J. Irrig. Drain. Eng., 133, 395-406, https:// doi.org/10.1061/(ASCE)0733-9437(2007)133:4(380).

— , and Coauthors, 2006: A recommendation on standardized surface resistance for hourly calculation of reference $\mathrm{ET}_{0}$ by the FAO 56 Penman-Monteith method. Agric. Water Manage., 81, 1-22, https://doi.org/10.1016/j.agwat.2005.03.007.

Alves, I., and L. S. Pereira, 2000: Modelling surface resistance from climatic variables? Agric. Water Manage., 42, 371-385, https:// doi.org/10.1016/S0378-3774(99)00041-4.

— resistances of complete cover crops: How good is the "big leaf"? Trans. ASAE, 41, 345-351, https://doi.org/10.13031/2013.17184.

Anadranistakis, M., P. Kerkides, A. Liakatas, S. Alexandris, and A. Poulovasilis, 1999: How significant is the usual assumption of neutral stability in evapotranspiration estimating models? Meteor. App., 6, 155-158, https://doi.org/ $10.1017 / \mathrm{S} 1350482799001127$.

—, A. Liakatas, P. Kerkides, S. Rizos, J. Gavanosis, and A. Poulovassilis, 2000: Crop water requirements model tested for crops grown in Greece. Agric. Water Manage., 45, 297-316, https://doi.org/10.1016/s0378-3774(99)00106-7.

Anderson, R. G., and D. Wang, 2014: Energy budget closure observed in paired Eddy covariance towers with increased and continuous daily turbulence. Agric. For. Meteor., 184, 204-209, https://doi.org/10.1016/j.agrformet.2013.09.012.

Anthoni, P. M., A. Freibauer, O. Kolle, and E.-D. Schulz, 2004: Winter wheat carbon exchange in Thuringia, Germany. Agric. For. Meteor., 121, 55-67, https://doi.org/10.1016/S0168-1923(03)00162-X.

Aubinet, M., T. Vesala, and D. Papale, 2012: Eddy covariance measurements over lakes. Eddy Covariance: A Practical Guide to Measurement and Data Analysis, T. Vesala, W. Eugster, and A. Ojala, Eds., Springer, 365-376, https://doi.org/10.1007/97894-007-2351-1.

Bailey, W. G., and J. A. Davies, 1981: Bulk stomatal resistance control on evaporation. Bound.-Layer Meteor., 20, 401-415, https://doi.org/10.1007/BF00122291.

Bastidas-Obando, E., W. G. M. Bastiaanssen, and C. Jarmain, 2017: Estimation of transpiration fluxes from rainfed and irrigated sugarcane in South Africa using a canopy resistance and crop coefficient model. Agric. Water Manage., 181, 94-107, https:// doi.org/10.1016/j.agwat.2016.11.024.

Belder, P., B. Bouman, R. Cabangon, L. Guoan, E. Quilang, L. Yuanhua, J. Spiertz, and T. Tuong, 2004: Effect of watersaving irrigation on rice yield and water use in typical lowland conditions in Asia. Agric. Water Manage., 65, 193-210, https:// doi.org/10.1016/j.agwat.2003.09.002.

Brunet, Y., J. J. Finnigan, and M. R. Raupach, 1994: A wind tunnel study of air flow in waving wheat: Single-point velocity statistics. Bound.-Layer Meteor., 70, 95-132, https://doi.org/ 10.1007/BF00712525.

Castellvi, F., A. Martínez-Cob, and O. Pérez-Coveta, 2006: Estimating sensible and latent heat fluxes over rice using surface renewal. Agric. For. Meteor., 139, 164-169, https://doi.org/10.1016/ j.agrformet.2006.07.005.

Chávez, J. L., T. A. Howell, and K. S. Copeland, 2009: Evaluating eddy covariance cotton ET measurements in an advective environment with large weighing lysimeters. Irrig. Sci., 28, 35-50, https://doi.org/10.1007/s00271-009-0179-7.

Chen, H., D. Yang, and H. Lü, 2013: Comparison of temporal extrapolation methods for evapotranspiration over variant underlying croplands. Trans. Chin. Soc. Agric. Eng., 29, 73-81, https://doi.org/10.3969/j.issn.1002-6819.2013.06.010.

Chowdary, V., Y. Srivastava, V. Chandran, and A. Jeyaram, 2009: Integrated water resource development plan for sustainable management of Mayurakshi watershed, India using remote sensing and GIS. Water Resour. Manage., 23, 1581-1602, https://doi.org/10.1007/s11269-008-9342-9.

Cleugh, H. A., R. Leuning, Q. Mu, and S. W. Running, 2007: Regional evaporation estimates from flux tower and MODIS satellite data. Remote Sens. Environ., 106, 285-304, https:// doi.org/10.1016/j.rse.2006.07.007.

Colaizzi, P. D., S. R. Evett, T. A. Howell, and J. A. Tolk, 2006: Comparison of five models to scale daily evapotranspiration from one-time-of-day measurements. Trans. ASABE, 49, 1409-1417, https://doi.org/10.13031/2013.22056.

Ding, Y., W. Wang, R. Song, Q. Shao, X. Jiao, and W. Xing, 2017: Modeling spatial and temporal variability of the impact of 
climate change on rice irrigation water requirements in the middle and lower reaches of the Yangtze River, China. Agric. Water Manage., 193, 89-101, https://doi.org/10.1016/ j.agwat.2017.08.008.

Dupont, S., and E. G. Patton, 2012: Momentum and scalar transport within a vegetation canopy following atmospheric stability and seasonal canopy changes: The CHATS experiment. Atmos. Chem. Phys., 12, 5913-5935, https://doi.org/10.5194/ acp-12-5913-2012.

Ershadi, A., M. F. Mccabe, J. P. Evans, and E. F. Wood, 2015: Impact of model structure and parameterization on PenmanMonteith type evaporation models. J. Hydrol., 525, 521-535, https://doi.org/10.1016/j.jhydrol.2015.04.008.

Falge, E., and Coauthors, 2001a: Gap filling strategies for defensible annual sums of net ecosystem exchange. Agric. For. Meteor., 107, 43-69, https://doi.org/10.1016/S0168-1923(00) 00225-2.

, and Coauthors, 2001b: Gap filling strategies for long term energy flux data sets. Agric. For. Meteor., 107, 71-77, https:// doi.org/10.1016/S0168-1923(00)00235-5.

Farah, H. O., W. G. M. Bastiaanssen, and R. A. Feddes, 2004: Evaluation of the temporal variability of the evaporative fraction in a tropical watershed. Int. J. Appl. Earth Obs. Geoinf., 5, 129-140, https://doi.org/10.1016/j.jag.2004.01.003.

Finnigan, J. J., R. Clement, Y. Malhi, R. Leuning, and H. A. Cleugh, 2003: A re-evaluation of long-term flux measurement techniquesPart I: Averaging and coordinate rotation. Bound.-Layer Meteor., 107, 1-48, https://doi.org/10.1023/A:1021554900225.

Foken, T., 2008: The energy balance closure problem: An overview. Ecol. Appl., 18, 1351-1367, https://doi.org/10.1890/060922.1.

_- M. Aubinet, J. J. Finnigan, M. Lecterc, M. Mauder, and U. K. T. P. Paw, 2011: Results of a panel discussion about the energy balance closure correction for trace gases. Bull. Amer. Meteor. Soc., 92, ES13-ES18, https://doi.org/10.1175/ 2011BAMS3130.1.

Gao, Z., L. Bian, and X. Zhou, 2003: Measurements of turbulent transfer in the near-surface layer over a rice paddy in China. J. Geophys. Res., 108, 4387, https://doi.org/10.1029/ 2002JD002779.

Gebler, S., H. J. Hendricks Franssen, T. Pütz, H. Post, M. Schmidt, and H. Vereecken, 2015: Actual evapotranspiration and precipitation measured by lysimeters: A comparison with eddy covariance and tipping bucket. Hydrol. Earth Syst. Sci., 19, 2145-2161, https://doi.org/10.5194/hess-19-2145-2015.

Gentine, P., D. Entekhabi, A. Chehbouni, G. Boulet, and B. Duchemin, 2007: Analysis of evaporative fraction diurnal behaviour. Agric. For. Meteor., 143, 13-29, https://doi.org/10.1016/ j.agrformet.2006.11.002.

Guo, Y., Y. Dong, H. Dang, J. Dong, and G. Wei, 2014: Evapotranspiration and transpiration of maize in two time scales and the environmental effects. Res. Sci., 35, 294-303.

Han, S., H. Hu, D. Yang, and F. Tian, 2011: A complementary relationship evaporation model referring to the granger model and the advection-aridity model. Hydrol. Processes, 25, 2094-2101, https://doi.org/10.1002/hyp.7960.

Hanisch, S., C. Lohrey, and A. Buerkert, 2015: Dewfall and its ecological significance in semi-arid coastal south-western Madagascar. J. Arid Environ., 121, 24-31, https://doi.org/ 10.1016/j.jaridenv.2015.05.007.

Hoedjes, J. C. B., A. Chehbouni, F. Jacob, J. Ezzahar, and G. Boulet, 2008: Deriving daily evapotranspiration from remotely sensed instantaneous evaporative fraction over olive orchard in semi-arid Morocco. J. Hydrol., 354, 53-64, https:// doi.org/10.1016/j.jhydrol.2008.02.016.

Hu, J. C., J. B. Zhang, B. Z. Zhao, and A. N. Zhu, 2005: Estimating diurnal variation of winter wheat canopy resistance at different growth stages. Guangai Paishui Xuebao, 24 (2), 1-4.

Irmak, S., D. Mutiibwa, J. Payero, T. Marek, and D. Porter, 2013: Modeling soybean canopy resistance from micrometeorological and plant variables for estimating evapotranspiration using one-step Penman-Monteith approach. J. Hydrol., 507, 1-18, https://doi.org/10.1016/j.jhydrol.2013.10.008.

Jiang, X., S. Kang, L. Tong, and F. Li, 2016: Modification of evapotranspiration model based on effective resistance to estimate evapotranspiration of maize for seed production in an arid region of northwest China. J. Hydrol., 538, 194-207, https://doi.org/10.1016/j.jhydrol.2016.04.002.

Kabela, E. D., B. K. Hornbuckle, M. H. Cosh, M. C. Anderson, and M. L. Gleason, 2009: Dew frequency, duration, amount and distribution in corn and soybean during SMEX05. Agric. For. Meteor., 149, 11-24, https://doi.org/10.1016/j.agrformet.2008.07.002.

Kalma, J. D., and I. R. Calder, 1994: Land surface processes in large scale hydrology. WMO Operational Hydrology Rep. 40, 60 pp., https://library.wmo.int/doc_num.php?explnum_id=1701.

_, T. McVicar, and M. McCabe, 2008: Estimating land surface evaporation: A review of methods using remotely sensed surface temperature data. Surv. Geophys., 29, 421-469, https:// doi.org/10.1007/s10712-008-9037-z.

Kang, S., B. Gu, T. Du, and J. Zhang, 2003: Crop coefficient and ratio of transpiration to evapotranspiration of winter wheat and maize in a semi-humid region. Agric. Water Manage., 59, 239-254, https://doi.org/10.1016/S0378-3774(02)00150-6.

Katerji, N., and G. Rana, 2006: Modelling evapotranspiration of six irrigated crops under Mediterranean climate conditions. Agric. For. Meteor., 138, 142-155, https://doi.org/10.1016/ j.agrformet.2006.04.006.

- — - and S. Fahed, 2011: Parameterizing canopy resistance using mechanistic and semi-empirical estimates of hourly evapotranspiration: Critical evaluation for irrigated crops in the Mediterranean. Hydrol. Processes, 25, 117-129, https:// doi.org/10.1002/hyp.7829.

Kato, Y., A. Henry, D. Fujita, K. Katsura, N. Kobayashi, and R. Serraj, 2011: Physiological characterization of introgression lines derived from an indica rice cultivar, IR64, adapted to drought and water-saving irrigation. Field Crops Res., 123, 130-138, https://doi.org/10.1016/j.fcr.2011.05.009.

Kelliher, F. M., R. Leuning, M. R. Raupach, and E. D. Schulze, 1995: Maximum conductances for evaporation from global vegetation types. Agric. For. Meteor., 73, 1-16, https://doi.org/ 10.1016/0168-1923(94)02178-M.

Kljun, N., P. Calanca, M. P. Rotach, and H. P. Schmid, 2004: A simple parameterization for flux footprint predictions. Bound.-Layer Meteor., 112, 503-523, https://doi.org/10.1023/B: BOUN.0000030653.71031.96.

Lecina, S., A. Martínez-Cob, P. J. Pérez, F. J. Villalobos, and J. J. Baselga, 2003: Fixed versus variable bulk canopy resistance for reference evapotranspiration estimation using the Penman-Monteith equation under semiarid conditions. Agric. Water Manage., 60, 181-198, https://doi.org/10.1016/S0378-3774(02)00174-9.

Linquist, B., and Coauthors, 2015: Water balances and evapotranspiration in water-and dry-seeded rice systems. Irrig. Sci., 33, 375-385, https://doi.org/10.1007/s00271-015-0474-4.

Liu, G. S., Y. Liu, and D. Xu, 2011: Comparison of evapotranspiration temporal scaling methods based on lysimeter measurements. J. Remote Sens., 15, 270-280. 
—_, M. Hafeez, Y. Liu, D. Xu, and C. Vote, 2012: A novel method to convert daytime evapotranspiration into daily evapotranspiration based on variable canopy resistance. J. Hydrol., 414-415, 278-283, https://doi.org/10.1016/j.jhydrol.2011.10.042.

Liu, B., J. C. Hu, X. L. Zhao, X. S. Zhang, and F. C. Zhang, 2015: Error analysis on evapotranspiration estimation of paddy rice field by Penman-Monteith model. Chin. J. Agrometeor., 36, 24-32.

Liu, X., S. Yang, J. Xu, J. Zhang, and J. Liu, 2017: Effects of soil heat storage and phase shift correction on energy balance closure of paddy fields. Atmosfera, 30, 39-52, https://doi.org/ 10.20937/ATM.2017.30.01.04.

_ J. Xu, S. Yang, and J. Zhang, 2018a: Rice evapotranspiration at the field and canopy scales under water-saving irrigation. Meteor. Atmos. Phys., 130, 227-240, https://doi.org/10.1007/ s00703-017-0507-z.

,,,,---- and Y. Wang, 2018b: Vapor condensation in rice fields and its contribution to crop evapotranspiration in the subtropical monsoon climate of China. J. Hydrometeor., 19, 1043-1057, https://doi.org/10.1175/JHM-D-17-0201.1.

Malek, E., G. E. Bingham, and G. D. Mccurdy, 1992: Continuous measurement of aerodynamic and alfalfa canopy resistances using the Bowen ratio-energy balance and Penman-Monteith methods. Bound.-Layer Meteor., 59, 187-194, https://doi.org/ 10.1007/BF00120694.

— G. D. McCurdy, and B. Giles, 1999: Dew contribution to the annual water balance in semi-arid desert valleys. J. Arid Environ., 42, 71-80, https://doi.org/10.1006/jare.1999.0506.

Masseroni, D., G. Ravazzani, C. Corbari, and M. Mancini, 2012: Turbulence integral length and footprint dimension with reference to experimental data measured over maize cultivation in Po Valley, Italy. Atmosfera, 25, 183-198.

_ , G. Ercolani, C. Corbari, and M. Mancini, 2013: Accuracy of turbulent flux measurements through the use of high frequency data by eddy covariance tower: The case study of Landriano (PV), Italy. Ital. J. Agrometeor., 3, 5-12.

Mauder, M., C. Liebethal, M. Göckede, J. P. Leps, F. Beyrich, and T. Foken, 2006: Processing and quality control of flux data during LITFASS-2003. Bound.-Layer Meteor., 121, 67-88, https://doi.org/10.1007/s10546-006-9094-0.

McNaughton, K. G., and P. G. Jarvis, 1991: Effects of spatial scale on stomatal control of transpiration. Agric. For. Meteor., 54, 279-302, https://doi.org/10.1016/0168-1923(91)90010-N.

Meyers, T., and S. Hollinger, 2004: An assessment of storage terms in the surface energy balance of maize soybean. Agric. For. Meteor., 125, 105-115, https://doi.org/10.1016/ j.agrformet.2004.03.001.

Ministry of Water Resources of China, 2016: China Water Resources Bulletin. Accessed 17 August 2019, http://www.mwr.gov.cn/sj/ tjgb/szygb/201707/t20170711_955305.html.

Mu, Q., M. Zhao, and S. W. Running, 2011: Improvements to a MODIS global terrestrial evapotranspiration algorithm. Remote Sens. Environ., 115, 1781-1800, https://doi.org/10.1016/ j.rse.2011.02.019.

Ortega-Farias, S., C. Poblete-Echeverría, and N. Brisson, 2010: Parameterization of a two-layer model for estimating vineyard evapotranspiration using meteorological measurements. Agric. For. Meteor., 150, 276-286, https://doi.org/ 10.1016/j.agrformet.2009.11.012.

Oue, H., 2005: Influences of meteorological and vegetational factors on the partitioning of the energy of a rice paddy field. Hydrol. Processes, 19, 1567-1583, https://doi.org/10.1002/ hyp.5589.
Patton, E. G., P. P. Sullivan, R. H. Shaw, J. J. Finnigan, and J. C. Weil, 2016: Atmospheric stability influences on coupled boundary layer and canopy turbulence. J. Atmos. Sci., 73, 1621-1647, https://doi.org/10.1175/JAS-D-15-0068.1.

Perez, P. J., S. Lecina, F. Castellvi, A. Martínez-Cob, and F. J. Villalobos, 2006: A simple parameterization of bulk canopy resistance from climatic variables for estimating hourly evapotranspiration. Hydrol. Processes, 20, 515-532, https:// doi.org/10.1002/hyp.5919.

Rana, G., N. Katerji, and M. Mastrorilli, 1997: Validation of a model of actual evapotranspiration for water stressed soybeans. Agric. For. Meteor., 86, 215-224, https://doi.org/10.1016/ S0168-1923(97)00009-9.

Shuttleworth, W. J., 1989: FIFE: The variation in energy partition at surface flux sites. IAHS Publ., 186, 67-74.

Tang, R. L., B. Tang, H. Wu, and Z. L. Li, 2015: On the feasibility of temporally upscaling instantaneous evapotranspiration using weather forecast information. Int. J. Remote Sens., 36, 49184935, https://doi.org/10.1080/01431161.2015.1029597.

Tao, F., and Coauthors, 2013: Single rice growth period was prolonged by cultivars shifts but yield was damaged by climate change during 1981-2009 in China, and late rice was just opposite. Global Change Biol., 19, 3200-3209, https://doi.org/ 10.1111/gcb.12250.

Todorovic, M., 1999: Single-layer evapotranspiration model with variable canopy resistance. J. Irrig. Drain. Eng., 125, 235-245, https://doi.org/10.1061/(ASCE)0733-9437(1999)125:5(235).

Ueyama, M., and Coauthors, 2012: Influences of various calculation options on heat, water and carbon fluxes determined by open- and closed- path eddy covariance methods. Tellus, 64B, 19048, https://doi.org/10.3402/tellusb.v64i0.19048.

Valentijn, R., N. Pauwels, and S. Roeland, 2006: Comparison of different methods to measure and model actual evapotranspiration rates for a wet sloping grassland. Agric. Water Manage., 82, 1-24, https://doi.org/10.1016/j.agwat.2005.06.001.

Van Zyl, W. H., and J. M. De Jager, 1987: Accuracy of the PenmanMonteith equation adjusted for atmospheric stability. Agric. For. Meteor., 41, 57-64, https://doi.org/10.1016/0168-1923(87)90069-4.

Verhoef, A., A. Diaz-Espejo, J. R. Knight, L. Villagarcia, and J. E. Fernandez, 2006: Adsorption of water vapour by bare soil in an olive grove in southern Spain. J. Hydrometeor., 7, 1011-1027, https://doi.org/10.1175/JHM556.1.

Verstraeten, W. W., F. Veroustraete, and J. Feyen, 2005: Estimating evapotranspiration of European forests from NOAA-imagery at satellite overpass time: Towards an operational processing chain for integrated optical and thermal sensor data products. Remote Sens. Environ., 96, 256-276, https://doi.org/10.1016/j.rse.2005.03.004.

Wang, K., and R. E. Dickinson, 2012: A review of global terrestrial evapotranspiration: Observation, modeling, climatology, and climatic variability. Rev. Geophys., 50, 93-102, https://doi.org/ 10.1029/2011RG000373.

Wilson, K., and Coauthors, 2002: Energy balance closure at FLUXNET sites. Agric. For. Meteor., 113, 223-243, https:// doi.org/10.1016/S0168-1923(02)00109-0.

Xu, J., S. Peng, S. Yang, and W. Wang, 2012: Ammonia volatilization losses from a rice paddy with different irrigation and nitrogen managements. Agric. Water Manage., 104, 184-192, https://doi.org/10.1016/j.agwat.2011.12.013.

_- X. Liu, S. Yang, Z. Qi, and Y. Wang, 2017: Modeling rice evapotranspiration under water-saving irrigation by calibrating canopy resistance model parameters in the Penman-Monteith equation. Agric. Water Manage., 182, 55-66, https://doi.org/ 10.1016/j.agwat.2016.12.010. 
Yan, H., H. Shi, O. Hiroki, C. Zhang, Z. Xue, B. Cai, and G. Wang, 2015: Modeling bulk canopy resistance from climatic variables for predicting hourly evapotranspiration of maize and buckwheat. Meteor. Atmos. Phys., 127, 305-312, https://doi.org/ 10.1007/s00703-015-0369-1.

Yang, J., W. Xiong, X. Yang, Y. Cao, and L. Feng, 2014: Geographic variation of rice yield response to past climate change in China. J. Integr. Agric., 13, 1586-1598, https:// doi.org/10.1016/S2095-3119(14)60803-0.

Zhang, L., and R. Lemeur, 1995: Evaluation of daily evapotranspiration estimates from instantaneous measurements. Agric. For. Meteor., 74, 139-154, https://doi.org/10.1016/ 0168-1923(94)02181-I.
Zhang, Q., S. Wang, F. L. Yang, P. Yue, T. Yao, and W. Y. Wang, 2015: Characteristics of dew formation and distribution, and its contribution to the surface water budget in a semi-arid region in China. Bound.-Layer Meteor., 154, 317-331, https:// doi.org/10.1007/s10546-014-9971-x.

Zhao, P., S. Li, F. Li, T. Du, L. Tong, and S. Kang, 2015: Comparison of dual crop coefficient method and Shuttleworth-Wallace model in evapotranspiration partitioning in a vineyard of northwest China. Agric. Water Manage., 160, 41-56, https:// doi.org/10.1016/j.agwat.2015.06.026.

Zhou, Y., S. H. Shen, and H. W. Zhang, 1994: A study of the effect of atmospheric stability on accuracy of field evapotranspiration (ET). J. Nanjing Inst. Meteor., 17, 93-96. 